\title{
WestVirginiaUniversity
}

THE RESEARCH REPOSITORY @ WVU

Graduate Theses, Dissertations, and Problem Reports

2015

\section{The Impact of Autonomous Vehicles on Freeway Throughput}

Abdullah Maarafi

Follow this and additional works at: https://researchrepository.wvu.edu/etd

\section{Recommended Citation}

Maarafi, Abdullah, "The Impact of Autonomous Vehicles on Freeway Throughput" (2015). Graduate Theses, Dissertations, and Problem Reports. 6129.

https://researchrepository.wvu.edu/etd/6129

This Thesis is protected by copyright and/or related rights. It has been brought to you by the The Research Repository @ WVU with permission from the rights-holder(s). You are free to use this Thesis in any way that is permitted by the copyright and related rights legislation that applies to your use. For other uses you must obtain permission from the rights-holder(s) directly, unless additional rights are indicated by a Creative Commons license in the record and/ or on the work itself. This Thesis has been accepted for inclusion in WVU Graduate Theses, Dissertations, and Problem Reports collection by an authorized administrator of The Research Repository @ WVU. For more information, please contact researchrepository@mail.wvu.edu. 


\title{
The Impact of Autonomous Vehicles on Freeway Throughput
}

\author{
By \\ Abdullah Maarafi \\ Thesis submitted to the \\ Benjamin M. Statler College of Engineering and Mineral Resources \\ at West Virginia University \\ in partial fulfillment of the requirements for the degree of \\ Master of Science \\ in Civil Engineering
}

\begin{abstract}
Committee members
Dr. Avinash Unnikrishnan, Committee Chairperson

Dr. Radhey Sharma, Co-Chair

Dr. Antarpreet Jutla

Department of Civil and Environmental Engineering

Morgantown, West Virginia
\end{abstract}

2015

Keywords: Car Following Model, VISSIM, Autonomous Vehicles, Throughput, Freeway, Microscopic Traffic Simulation

Copyright 2015 Abdullah Maarafi 


\title{
ABSTRACT \\ The Impact of Autonomous Vehicles on Freeway Throughput
}

\author{
Abdullah Maarafi
}

Autonomous vehicles are expected to provide a number of benefits to the individual, road infrastructure and the society from the perspective of safety and efficiency. The use of autonomous vehicles is expected to increase freeway throughput, allowing vehicle groups travelling together with a shorter headway time resulting in a reduction of traffic congestion.

The purpose of this research was to use microsimulation software, VISSIM, to test the impact of autonomous vehicles on freeway throughput, delay, and travel time. A realistic corridor of I-79 and a conceptual corridor were modeled to understand how mixed traffic flow conditions could impact the freeway throughput. In addition, the same corridors were used to test the impact of various lane configurations on efficiency of mixed traffic flow including regular and autonomous vehicles.

Our results have shown that incorporation of autonomous vehicles with regular vehicles can increase the freeway throughput. The increase observed in our study has reached above $17 \%$ of freeway benefits with $60 \%$ or higher of autonomous vehicles penetration rate. However, using autonomous vehicles with lane configuration have shown a negative impact on freeway throughput. That is due to the congestion caused by regular vehicles mainly at the exits and entrances of the freeway 


\section{ACKNOWLEDGEMENTS}

I really don't know how to express my sincere appreciation in one word to the people who helped me in many ways to finish this thesis.

I would like to thank Dr.Avinash Unnikrishnan, first, for giving me the opportunity to work with him and the Transportation Program at WVU, and second for guiding me through the process of developing, testing and writing my thesis. It was a pleasure working with him and gaining knowledge and experience through the transportation program at WVU. I would have never done it without his continuous guidance and support.

Special thanks my committee members, Dr. Radhey Sharma and Dr. Antarpreet Jutla for taking the time to review and evaluate my project.

I would also like to thank my fellow graduate students for the assistance in the lab while I was in the process of simulating and I want to wish them luck with their projects.

Last but not the least, I would like to thank my parents for their unconditional love and support they rendered me throughout my life. Today, whatever I have achieved it would not have been possible without them. Their patience and support allowed me to focus on my work with minimal distractions throughout the past year. I thank God for giving me such a wonderful gift in my life. 


\section{TABLE OF CONTENTS}

\section{Table of Contents}

ABSTRACT …........................................................................................................ii

ACKNOWLEDGEMENTS .......................................................................... iii

TABLE OF CONTENTS .................................................................................... iv

LIST OF FIGURES....................................................................................... vi

LIST OF TABLES.........................................................................................iv

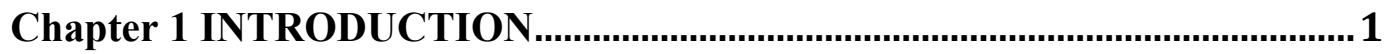

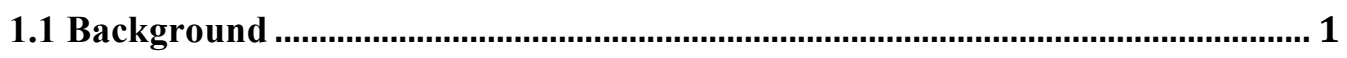

1.2 Impact of Autonomous Vehicles on Freeway Capacity .................................... 3

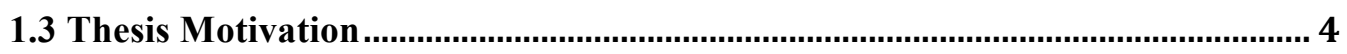

1.4 Thesis Outline ............................................................................................. 4

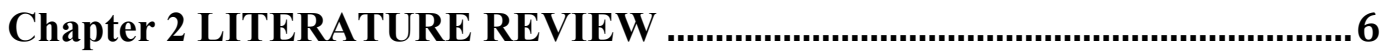

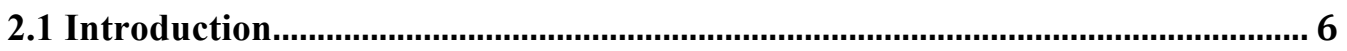

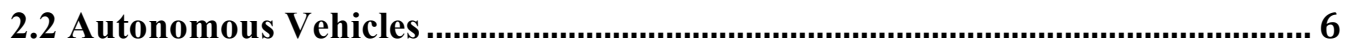

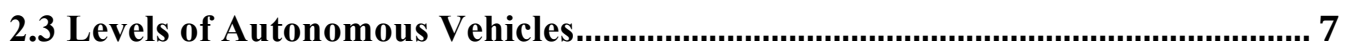

2.4 Benefits of Autonomous Vehicles....................................................................... 8

2.5 Problems of Autonomous Vehicles................................................................... 9

2.6 Impacts of Autonomous Vehicles on Travel Time, Capacity and Delay........... 9

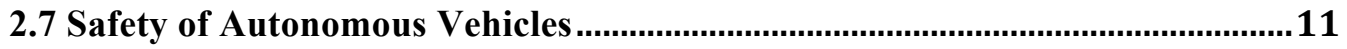

2.8 Market Penetration ............................................................................................. 13

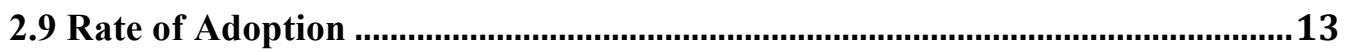

2.10 Capacity and Fleet mix ................................................................................... 14

2.11 Availability of Autonomous Vehicles in the Market ......................................15

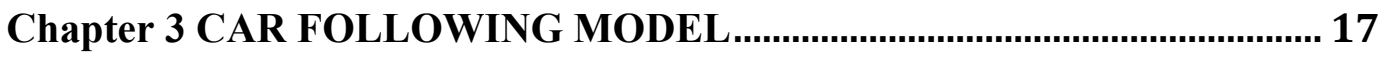

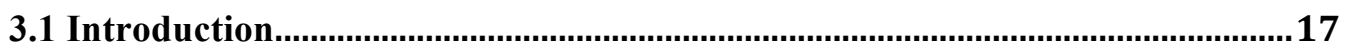

3.2 Car Following Model....................................................................................... 17

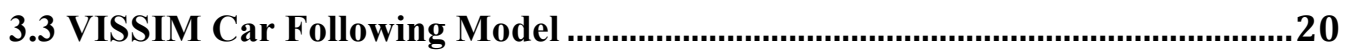

3.4 Weidemann 1999 Car Following Model............................................................22

Chapter 4 RESEARCH METHODOLOGY AND RESULTS ..................... 24

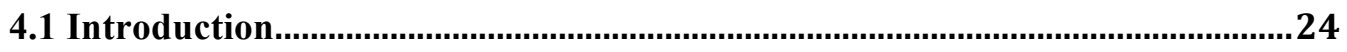

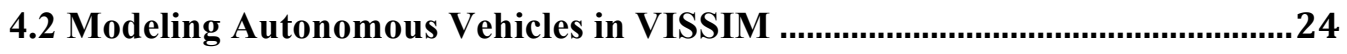

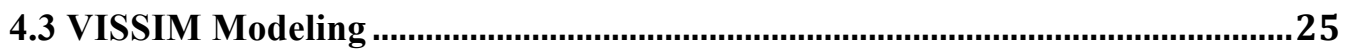

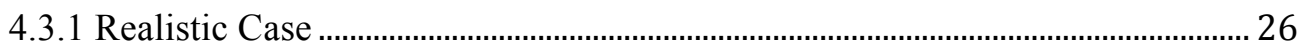

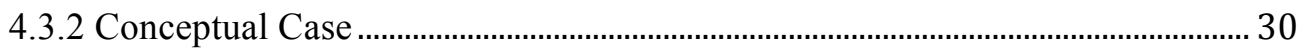




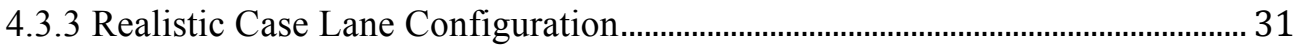

4.3.4 Conceptual Case Lane Configuration.................................................................... 32

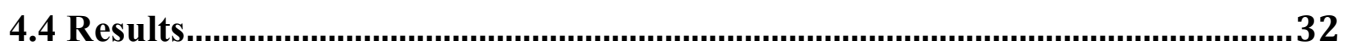

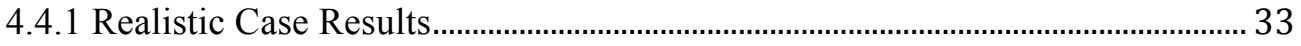

4.4.2 Conceptual Case Results........................................................................................ 34

4.4.3 Realistic Case Lane Configuration Results ………............................................. 35

4.4.2 Conceptual Case Lane Configuration Results ..................................................... 36

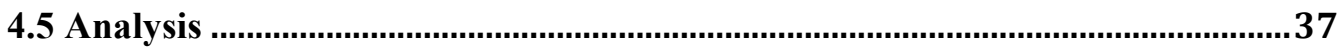

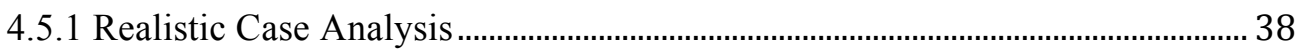

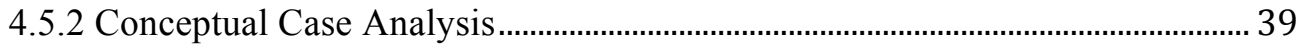

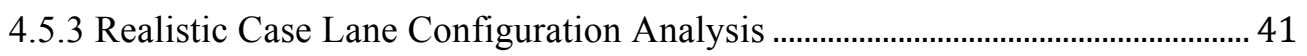

4.5.4 Conceptual Case Lane Configuration Analysis ..................................................... 42

Chapter 5 CONCLUSIONS AND RECCOMENDATIONS........................ 44

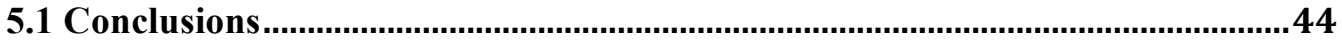

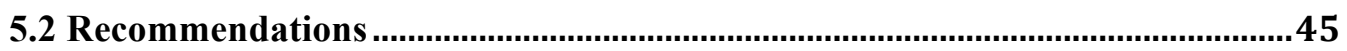

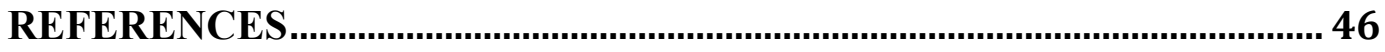

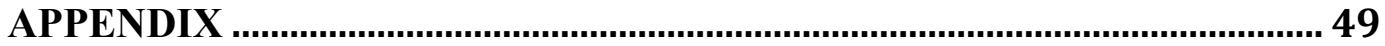




\section{LIST OF FIGURES}

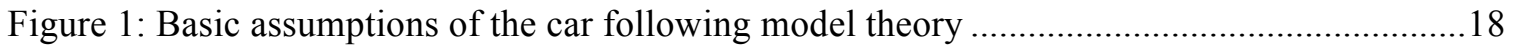

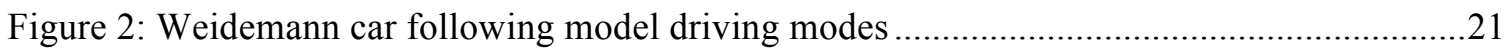

Figure 3: The I-79 section that was used to model the network in VISSIM .................................27

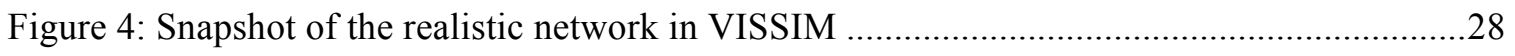

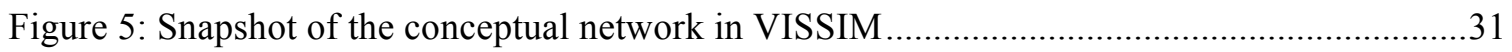

Figure 6: Comparison of throughput with respect to different autonomous vehicles presence at

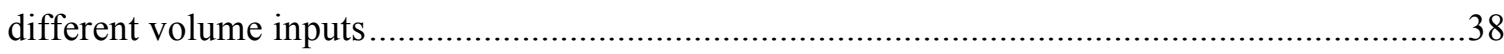

Figure 7: Comparison of throughput with respect to different autonomous vehicles presence at

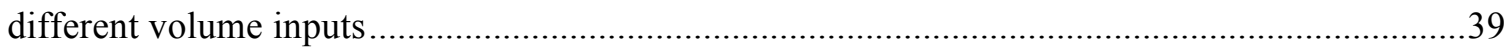

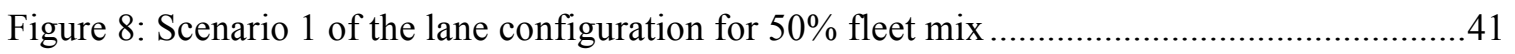

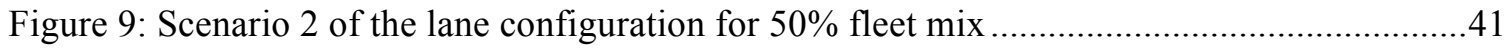

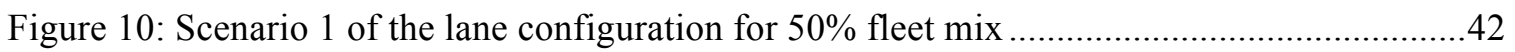

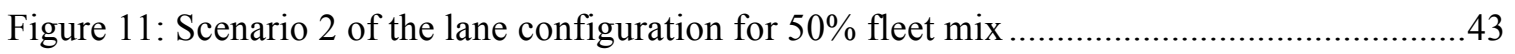




\section{LIST OF TABLES}

Table 1: Weidemann 99 calibrated parameters modeling the autonomous vehicles in VISSIM ...26

Table 2: Data summary for volume input of 2,400 vehicle/hour/lane with all 7 scenarios............33

Table 3: Data summary for volume input of 2,650 vehicle/hour/lane with all 7 scenarios.............33

Table 4: Data summary for volume input of 2,900 vehicle/hour/lane with all 7 scenarios............33

Table 5: Data summary for volume input of 3,150 vehicle/hour/lane with all 7 scenarios............33

Table 6: Data summary for volume input of 3,400 vehicle/hour/lane with all 7 scenarios............34

Table 7: Data summary for volume input of 2,350 vehicle/hour/lane with all 7 scenarios............34

Table 8: Data summary for volume input of 2,600 vehicle/hour/lane with all 7 scenarios............34

Table 9: Data summary for volume input of 2,850 vehicle/hour/lane with all 7 scenarios............35

Table 10: Data summary for volume input of 3,100 vehicle/hour/lane with all 7 scenarios...........35

Table 11: Data summary for volume input of 3,350 vehicle/hour/lane with all 7 scenarios...........35

Table 12: Data summary for volume input of 2,400 vehicle/hour/lane ........................................35

Table 13: Data summary for volume input of 2,650 vehicle/hour/lane .........................................36

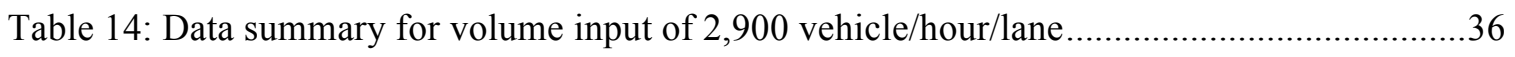

Table 15: Data summary for volume input of 3,150 vehicle/hour/lane ........................................36

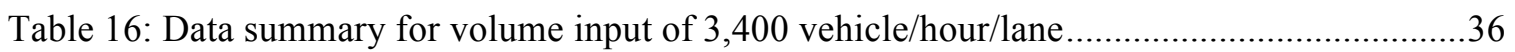

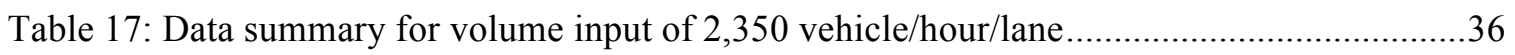

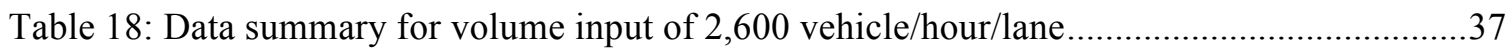

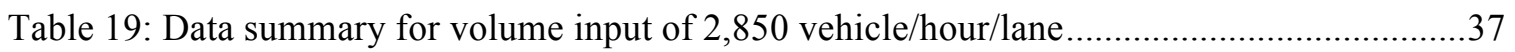

Table 20: Data summary for volume input of 3,100 vehicle/hour/lane ..........................................

Table 21: Data summary for volume input of 3,350 vehicle/hour/lane .......................................37 


\section{Chapter 1 INTRODUCTION}

\subsection{Background}

Autonomous vehicles refer to vehicles that have several of its functions automated, hence enabling the vehicles to be driven with or without human interaction (Litman, 2014). In the streets, they are mostly called driverless or robotic vehicles. Pinjari et al. (2013) stated that autonomous vehicles are vehicles that will be effectively driven by programmable instructions intended to enable the vehicles function as if they are operated by human beings. Functions such as driving, maneuvering, braking etc. With regards to the automated functions, different vehicles possess different sophistication of automation. This leads us to differentiating the autonomous vehicles according to their level of automation.

The National Highway Traffic and Safety Administration (NHTSA) have categorized autonomous vehicles in to five different levels, from zero to four, increasing in sophistication with the increase in level. Level 0, called No-Automation basically comprises of the conventional vehicles with no automation. The driver has complete control of all the functions of the vehicle. Level 1, referred to as Function-Specific Automation represents the first and lowest level of automation in the achievements of autonomous vehicles. Functions they perform are assistance in parallel parking, cruise control, and lane guidance. Other functions related to steering, accelerating, braking, and overtaking have to be performed by the driver.

Level 2 autonomous vehicles achieved the feat of assisting the vehicle when steering, and with feet off the pedals, under certain conditions. It also integrates multiples functions such as adaptive cruise control and lane centering. Level 3 vehicles, called 
Limited Self-Driving Automation can take overall control of the car while it operates. This presents a higher step in achievement than the previous two levels (Litman, 2014). All functions related to critical safety are under automation. If the driver is to take control, the automation forfeits all its control and lets the driver to be in charge.

The Level 4 vehicles are the highest level of autonomous vehicles. They are the Fully Self-Driving Automation that takes full control of the vehicle on the roadways. Many of Level 4 vehicles are undergoing numerous tests. Pinjari et al. (2013) reported that over 500,000 miles of roadway testing have been carried out by many automobile manufacturers, who believe that the merits of autonomous vehicles outweigh the negatives.

The numerous benefits of autonomous vehicles not only benefit the driver, they also have impacts on the roadway infrastructure and the society. The first obvious benefit is the cost incurred for driver services will reduce, as the need for drivers will decline. Taxis and private chauffeurs will not be required any longer. Similarly, drivers have less to do when behind the steering wheel, as automation will take control of every function of the car (Litman, 2014). This automation is expected to make roads safer due to a corresponding decrease in accidents caused by human disabilities such as drunk driving, by up to $90 \%$ (Rodoulis, 2014). As automation will take control, effects such as poor vision, loss of concentration, and drunk driving will be eliminated (Litman, 2014). Crash avoidance technologies like collision avoidance system (CAS) and other technologies like cooperative adaptive cruise control (CACC), vehicle-to-vehicle (V2V) and vehicleto-infrastructure (V2I) communications will enable safer travel of autonomous vehicles (Llorca et al., 2011; Talebpour and Mahmassani, 2015). 
Whereas on the other side of the coin, it is expected that roadway infrastructure will have to be modified to suit autonomous vehicles. It is also anticipated that more cost will be incurred in trying to maintain autonomous vehicles as well as purchasing and servicing them. Litman (2014) also pointed out that autonomous vehicles could aid security problems such as sending car bombs, hacking into their navigation systems, and gaining access to private data.

Market projections by Pinjari et al. (2013) and Biersterdt et al. (2014) state that autonomous vehicles will be available in many markets in the coming five to ten years. They will constitute the largest percentage of fleet on freeway lanes at different times in the future (Bierstedt et al., 2014). They are also expected to reduce delay (Anderson et al., 2014). It is important to mention that some autonomous vehicles are already plying highways across the world with features such as vehicle space monitoring, adaptive cruise control (ACC), lane and parking assists (Bierstedt et al., 2014).

\subsection{Impact of Autonomous Vehicles on Freeway Capacity}

When a large penetration of autonomous vehicles is witnessed, it will change and impact freeway capacity. This is due to the fact that headway distances of autonomous vehicles differ from human driving. The way humans will negotiate a turn, pull over, speed, and maintain headway between it and the next vehicle will be different from driverless cars.

Freeway parameters expected to be impacted include lane width sizes, number of turns, speed limits etc. With $40 \%$ penetration level of autonomous vehicles having cooperative adaptive cruise control (CACC), there can be up to $7 \%$ increase on freeway capacity (Jones and Philips, 2013). Their ability to maintain moving in lanes will also 
impact the sizes of the freeways, perhaps making them narrower. An additional ability for autonomous vehicles to drive closer to each other will reduce lateral distances between them, thus reducing lane width too (Levinson, 2015).

According to Bierstedt et al. (2014), at around 2035, when autonomous vehicle hit full penetration, they will be at about $25-35 \%$ traffic flow benefits. This is assuming autonomous vehicle regulations have not been normalized. By the time they do, a possible $45 \%$ or more reduction of vehicle delay is achievable. Moreover, Tientrakool et al. (2011) found out that freeway capacity will increase at a slow rate when the fleet penetration is at $30 \%$ or less, and it will start increasing at a higher rate when the fleet penetration starts increasing.

Overall and in the long run, when they reach full penetration and when vehicles are able to communicate with each other, freeway capacity is expected to increase.

\subsection{Thesis Motivation}

The motivation of this research is

- To apply a microsimulation framework to understand the impact of autonomous vehicles on freeway throughput, delay, and travel times.

- To study the impact of various freeway lane configuration on efficiency of mixed traffic flow including regular and autonomous vehicles.

\subsection{Thesis Outline}

This thesis is composed of five chapters. Following the research introduction in chapter 1, this research effort is structured as follows. The second chapter provides the literature review that was conducted in order to better understand autonomous vehicles 
and how they impact the freeway capacity. Chapter three provides a detailed review of the car following model in general and the car following model used in VISSIM. The forth chapter consist of the research methodology on how to model autonomous vehicles in VISSIM, results and the analysis of the results collected. Finally, the fifth chapter concludes with the conclusions of the study and the recommendations for future research. 


\section{Chapter 2 LITERATURE REVIEW}

\subsection{Introduction}

A literature review was conducted to determine research efforts related to the autonomous vehicles and how they can impact the freeway capacity, delay and travel time. In addition to discussing the topics covered in this thesis, the literature review was used to help develop a better understanding of the autonomous vehicles. Areas of interest include levels of the autonomous vehicles, pros and cons of the autonomous vehicles, safety, availability, market penetration, and rate of adoption of the autonomous vehicles. More importantly the percentage of autonomous vehicles presence and the impact they have on freeway capacity is also discussed in this chapter.

\subsection{Autonomous Vehicles}

According to Litman (2014), autonomous vehicles are regarded as vehicles that drive themselves. In other words, self-driving cars. In other definitions, they are called driverless or robotic. They operate with a set of programmed instructions enabling them to navigate streets, highways and freeways like normal human beings do (Pinjari et al., 2013). This sort of technology is similar to the autopilot mode pilots engage airplanes while flying. While planes cannot take off and land on autopilot mode, autonomous vehicles can start the engine, maneuver to prescribed locations, stop and turn off the engine. Many automobile manufacturers have produced autonomous vehicles and have carried out a series of test runs over 500,000 miles on major highways (Pinjari et al., 2013). 


\subsection{Levels of Autonomous Vehicles}

Autonomous vehicles have been categorized in to five different levels according to the National Highway Traffic and Safety Administration (NHTSA). Level 0 is called No-Automation, where the driver is in complete control of all functions of the vehicle (brake, steering, throttle, and motive power) at all times. Level 1 autonomous vehicles are called Function-specific Automation. This is the lowest level of advancement in autonomous vehicles. They perform only certain control functions such as automated parallel parking, lane guidance, and cruise control. The rest of the controlling functions are performed by the driver including acceleration, brakes, steering, and overtaking.

Level 2 autonomous vehicles are more advanced and automated than level 1 autonomous vehicles. NHTSA refer to them as Combined Function Automation. In Level 2 autonomous vehicles, feet can be off the pedal and hands off the steering wheel under certain conditions. There is integration of multiple control functions such as lane centering and adaptive cruise control. Like level 1 autonomous vehicles, drivers are responsible for the overall monitoring of the vehicle on the roadway.

Level 3 autonomous vehicles are referred to as Limited Self-Driving Automation and are far more advanced than the previous two (Litman, 2014). Drivers can sit back and relax while the automation takes control of the vehicle. A driver will only monitor the roadway when the automation triggers a transition back to the driver. All safety critical functions are under automation.

The Fully Self-Driving Automation is the level 4. They can fully drive themselves without needing human presence in the vehicle. The car can effectively undertake all functions of monitoring roadway conditions (Litman, 2014). 


\subsection{Benefits of Autonomous Vehicles}

Autonomous vehicles are expected to provide a number of benefits to the individual, road infrastructure, and the society. Each benefit though has an associated cost and depending on the level of the autonomous vehicles, benefits differ. But in general, the benefits of autonomous vehicles are found to be encouraging to continue the pursuit of achieving 100\% automation in vehicular movement.

The obvious benefits are the cost reduction of driver services. Drivers will be required to do less and there will be a reduction of commercial transport such as taxi. The obvious advantage to the car drivers is the reduction of stress of driving. While the vehicle is in automation, drivers can relax and engage in some other activities. Moreover, autonomous vehicles provide independent mobility for non-drivers, and therefore reduce the need for motorists to chauffeur non-driver, and to subsidize public transit (Litman, 2014).

Litman (2014) also mentioned that autonomous vehicles should increase road safety. Common accidents like collisions caused by drunk driving may reduce considerably. The vehicles will take control of driving and drivers with vision problems will not need to worry about putting themselves and the passengers at risk. The reduction of car accidents means that less money will be spend on crash repair costs and insurance premiums. Moreover, autonomous vehicles will also be able to operate safely in diverse conditions such as snow, rain, tunnels, unpaved roads, etc. (Litman, 2014).

The use of autonomous vehicles is expected to increase road capacity, allowing vehicle groups travelling together in narrower lanes and reduction in intersection stops resulting in a reduction of traffic congestion and roadway costs. Other benefits are 
increased fuel efficiency, reduction in air pollution, more efficient parking, and supporting shared vehicles. Litman (2014) also mentioned that the advocates of autonomous vehicles could also be potentially overstating the benefits.

\subsection{Problems of Autonomous Vehicles}

While autonomous vehicles enjoy numerous benefits, it is important to note that they have associated costs and problems. First is the expected increased cost of purchasing, servicing, and maintaining autonomous vehicles. Roadway infrastructure will also need to be modified as more and more autonomous vehicles are used. Problems associated with autonomous vehicles include system failures or being unsafe to use in some certain conditions, which will force the road users to take additional risk (Litman, 2014)

Use of autonomous vehicles could also help criminal activities such as terrorism in the form of sending car bombs, hacking of navigation systems of autonomous vehicles, and having access to exclusive privacy data. They could also raise social equity concerns by interfering with other modes of transportation safety and convenience. Overall, autonomous vehicles will render many drivers jobless and vehicle mechanics will have less repair to do because of reduced crashes. Thus autonomous vehicles may plunge the employment graph (Litman, 2014).

\subsection{Impacts of Autonomous Vehicles on Travel Time, Capacity and Delay}

Autonomous vehicles have both direct and indirect impacts on travel time, delay, and freeway capacity. For instance, in Litman (2013), classic examples of the discrepancies in the impacts of autonomous vehicles were given. In one scenario, Gary, a 
hard-working man, is only a responsible fellow when sober. When drunk, he engages in drunk driving thereby causing accidents and many impaired citations. If he continues to use normal vehicles, in the future, he might have caused a big crash or lose his drivers' license totally. If Gary were to switch to an autonomous vehicle, it will save him the trouble of impaired citations, zero accidents , and no ceased license. Therefore, increasing his lifetime. However, his vehicle ownership, travel and some external costs will increase (Litman, 2014). So, the total driving time, residential parking, and roadway costs will all increase, but with less high risk driving.

Another contrasting scenario given by Litman (2014) is about Bonnie who lives in a suburb. She occasionally needs a car to accomplish some things, but most of the times, she bikes to wherever she want. She enjoys car sharing and taxi services, but admitted they are expensive and slow in the suburbs. If she were to buy into an automated vehicle car sharing service against purchasing one herself, it will reduce travel time and car vehicle ownership. It will also reduce external costs (roadway) and residential parking demand.

According to Anderson et al. (2014), delay is expected to reduce with the addition of autonomous vehicles on the streets. There are two types of traffic congestions, recurrent delays congestion and non-recurrent delays congestion. Recurrent delays congestion are those that occur on the same location and in the same time on a daily basis, and that is due to the number of vehicles using the roads exceeding the road's capacity. Non-recurrent delays congestion are those that occur from special circumstances such as severe weather conditions, construction or roadwork, disabled vehicle or crash incidents. According to the Federal Highway Administration (FHWA), 
non-recurrent delays are responsible of half of all congestion delays that occur (FHWA, 2013). Both recurrent delays and non-recurrent delays are expected to decrease with the introduction of autonomous vehicles on the roadways (Anderson et al., 2014).

\subsection{Safety of Autonomous Vehicles}

Autonomous vehicles are expected to be safer than regular vehicles considering human factors like influence of alcohol, lack of attention, slow reaction times, lack of visibility etc. are removed. More than $90 \%$ of road accidents are estimated to be caused by human behavior (Rodoulis, 2014). The issues of the safety of autonomous vehicles are questioned when at times humans control vehicles, and situations are experienced where driver judgments will be required. If this arises, can the automation judge correctly? For instance, if there is an obstruction on the road such a stone, what will be the appropriate response of the autonomous vehicle? Switch lane, go off the road (only if a shoulder exists). Another important consideration is what if the object is not one to cause an accident, such as a cardboard box? The tricky situations that affect humans while driving will have to be addressed by autonomous vehicles before they can be proved to be safer than the current technology (Bierstedt et al., 2014). The level of acceptance of the testing has not been set for consumer and regulator acceptance, but it is likely to be three defects per million, a very high acceptance level (Bierstedt et al., 2014).

Many researchers have reported on the purported safety of autonomous vehicles over regular vehicles (Ni and Leung, 2011). Autonomous vehicles will make better decisions than humans because of the intelligent real time communication they will establish with traffic and weather systems. It will also eliminate incidents caused by human disabilities such as poor eyesight, drunk driving, and driving while using mobile 
phones (NHTSA, 2012). Talebpour and Mahmassani (2015) mentioned that autonomous vehicles are installed with better sensing, processing power, and communication technologies, thus, enabling them to advance current technology in the transportation sector, specifically in safety and reliability.

The technology Cooperative Adaptive Cruise Control (CACC) enables autonomous vehicles to travel safely in a convoy. Cooperative Adaptive Cruise Control (CACC) uses the behavior of other vehicles to automatically adjust its speed, relative speed, and spacing (Talebpour and Mahmassani, 2015). A report by NHSTA (2012) mentioned that the crash avoidance technologies that come with autonomous vehicles will prevent vehicle crashes in traffic congestion, where a large percentage of crashes occur for vehicles driven by humans.

Lorca et al. (2011) stated that autonomous vehicles can use the collision avoidance system (CAS) in order to prevent collision with pedestrians or vehicles such as bikes, cars, and trucks. The CAS executes in three steps- object detection, decision making, and actuation. Object detection is carried out by sensors that read the environment information. The decision making system then uses the information to decide on what next line-of-action to take in order to avoid the collision. And the final step, actuation, implements the decision through steering, braking or throttling, and endeavor to avoid the crash (Lorca et al., 2011).

The Internet communication technology of autonomous vehicles that allows individual vehicles to communicate with each other, in other words, vehicle-to-vehicle (V2V) communication enhances safety (Talebpour and Mahmassani, 2015). Another type of technology that makes them safe is the vehicle-to-infrastructure (V2I), in other words 
traffic management center. Vehicle-to-infrastructure (V2I) is wireless communication of safety and operational data between road infrastructure and vehicles with the sole intention of avoiding crashes.

A pre-cash safety (PCS) system prevents autonomous vehicles from clashing with pedestrians, infrastructures, and other vehicles (Hayashi et al., 2012). It uses wave radar and a stereo camera in detecting pedestrians, infrastructures and other vehicles, during the day or night time.

\subsection{Market Penetration}

Bierstedt et al. (2014) and Pinjari et al. (2013) mentioned that in the next five to ten years, autonomous vehicles will be present in many markets. Already, series of tests with distances more than 500,000 miles have been carried out with autonomous vehicles. This doesn't reflect failure in the much delayed arrival, but only means a normal transition, as with what happened to the acceptance of airbags in all vehicles, which took 15 years.

\subsection{Rate of Adoption}

Bierstedt et al. (2014) estimated that autonomous vehicles would be on the roads to such an extent that they would change how other transportation systems operate. They will make up the highest percentage of the fleet on exclusive freeway lanes between 2025-2030, mixed freeway lanes and ramps between 2030-2035, auto-dominated arterials between 2035-2040, multi-modal streets and intersections between 2040-2050, vehicle operating without a legal driver aboard on public streets and lots in $2050+$, and private streets and self-parking in private lots between 2040-2050. 


\subsection{Capacity and Fleet mix}

Both autonomous vehicles and connected vehicles will produce a net effect on freeway capacity and operations. But this depends on the percentage of each vehicle type of the fleet mix, operating parameters such as deceleration, acceleration, headway etc. and also the vehicles ability to respond to traffic conditions (Bierstedt et al., 2014).

Bierstedt et al. (2014) stated that in the initial mass launch of autonomous vehicles, there would be no significant impact on the highway capacity. They could degrade the highway capacity as safety-conscious conservative programming of vehicles speeds and headways reduce vehicle densities and flow (Bierstedt et al., 2014). In the

long run, when they hit full penetration and when vehicles are able to cooperate with one another, capacity is expected to increase. Autonomous vehicles are expected to have vehicle-to-vehicle communication and cooperation when it comes to negotiating maneuvers, right of way. This function will enable them to communicate with other autonomous vehicles on the way and agree on what vehicle should stop, and which vehicle should pass the T-junction.

Before then, Bierstedt et al. (2014) mentioned capacity benefits are only likely to be noticed on the freeways. That timeline is expected to be around post 2035 when the autonomous vehicles fleet mix might be at $25-35 \%$ traffic flow benefits. After which, when regulations regarding autonomous vehicles are normalized, there might be a $45 \%$ or more reduction of vehicle delays.

It is estimated by late in the decade of 2040s that the freeway capacity will increase, and that is when there is about $20-40 \%$ vehicle fleet penetration of autonomous vehicles (Reich, 2013). Furthermore, Shladover et al. (2012) mentioned that if 
autonomous vehicles with cooperative adaptive cruise control (CACC) are to have a $10 \%, 50 \%$ and $90 \%$ penetration level, the effective lanes' capacities will increase by up to $1 \%, 21 \%$ and $80 \%$ respectively. Van Arem et al. (2006) found that autonomous vehicles with cooperative adaptive cruise control (CACC) with penetration rate of less than $40 \%$ will not make a significant difference in roadway capacity. However, when the penetration rate exceeds $60 \%$, the impact on roadway capacity can be significantly noticed. Similarly, Jones and Philips (2013) found that positive impacts are noticeable when vehicles with cooperative cruise control (CACC) exceed $40 \%$ penetration rate at 60 mph. Moreover, Davis (2005) mentioned that with a penetration rate of $50 \%$ of autonomous vehicles with adaptive cruise control (ACC), capacity is expected to increase to more than 7\%. Tientrakool et al. (2011) found that capacity increases at a slow rate when the penetration rate of cooperative adaptive cruise control (CACC) vehicles is at $30 \%$ or less. However, the capacity starts increasing with a little higher rate when the penetration rate is at $85 \%$ and then it starts improving at higher rate when it exceeds that point.

\subsection{Availability of Autonomous Vehicles in the Market}

Bierstedt et al. (2014) reported that Level 1 Autonomous vehicles are already in the market. They possess features like vehicle space monitoring, lane assists, adaptive cruise control (ACC) and parking assist. The Mercedes S-Class 2014 has been around since 2013. Its facilities include lane assist, parking assist, autonomous steering, driver fatigue detection and acceleration/braking (Bierstedt et al., 2014). The 2014 BMW i3 has automation in acceleration, steering and braking. Google is expected to have autonomous 
vehicles in the market by 2018. By 2020, many car manufactures are expected to sell autonomous vehicles. 


\section{Chapter 3 CAR FOLLOWING MODEL}

\subsection{Introduction}

In order to model autonomous vehicles in VISSIM, it is very important to have a clear understanding of the car following model in general and the car following model in VISSIM. This chapter discusses the car following model and its important parameters, car following model used in VISSIM, and the Weidemann 1999 car following model used in VISSIM to complete this research.

\subsection{Car Following Model}

A vehicle is said to be free if it is unconstrained by another and moves at the speed it desires (Gomes et al., 2004). In the car following model, a driver's behavior is controlled with respect to the preceding vehicle in the same lane. A car is said to be following if there exists a vehicle in front constraining it, referred to as a leading or preceding car (Olstam et al., 2004). The car following model describes how one vehicle follows another vehicle in uninterrupted flow facilities. Different car following model theories have been developed to explain how a vehicle responds to the changes made by the vehicle ahead.

As mentioned above, the foundation of any car following model is the responsestimulus idea in which the following vehicle, vehicle B responds to the stimulus provided by leading vehicle, vehicle A. Let A be the $n^{\text {th }}$ vehicle and B the follower vehicle be the $(n+1)^{t h}$ vehicle. The distance of the vehicles to a fixed point at any time, $t$, can be represented by $X_{n}^{t}$ for car A and $X_{n+1}^{t}$ for vehicle B. The speed of vehicle A and B at a certain time is noted as $V_{n}^{t}$ and $V_{n+1}^{t}$, respectively. T, is an important parameter added to the microscopic model which accounts for the lag time or reaction time following vehicle 
$\mathrm{B}$ takes to respond to the changes in the leading Vehicle $\mathrm{A}$. T is also called the sensitivity coefficient.

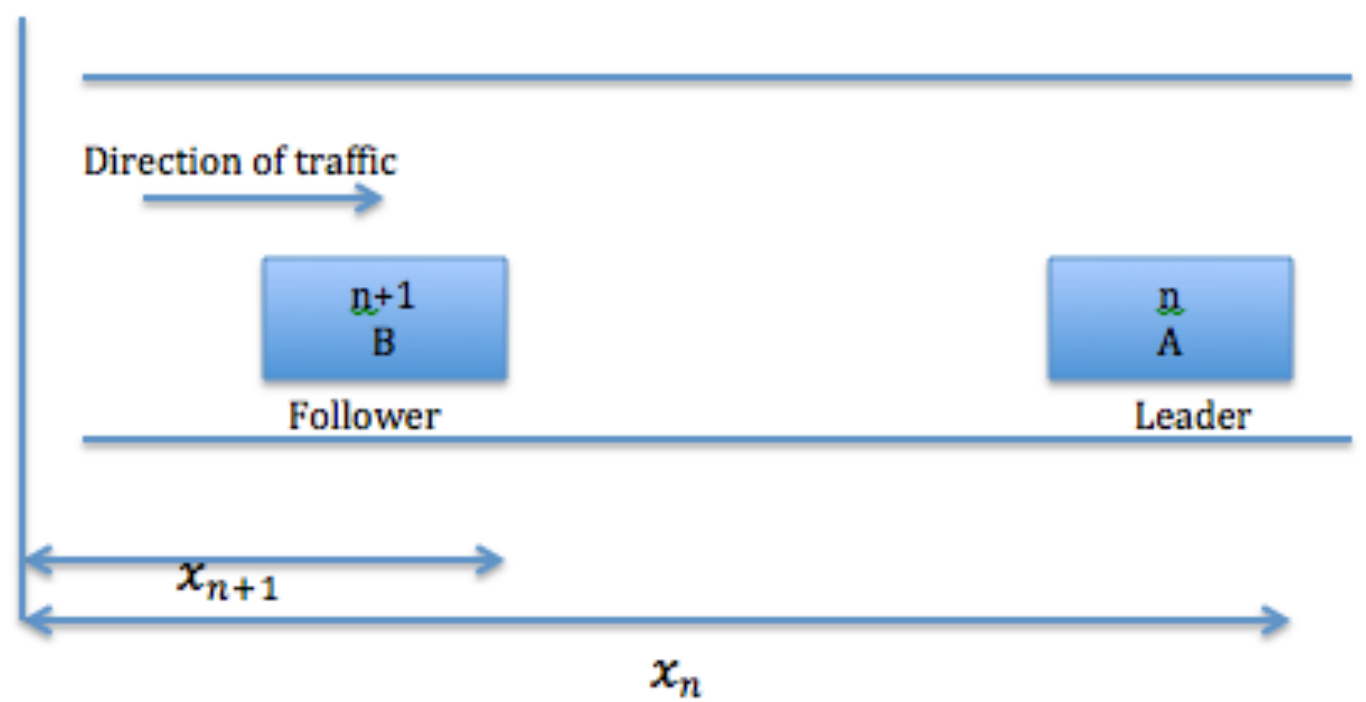

Figure 1: Basic assumptions of the car following model theory Source: Traffic and Highway Engineering $4^{\text {th }}$ Edition

In the microscopic model, the response is observed as the acceleration, $a_{n+1}$, where as the stimulus is a function of multiple variables including speed of the following vehicle, relative speed of the vehicle ahead and distance measure from the front bumper of the leading vehicle to the front bumper of the following vehicle, called the distance headway.

There are two assumptions that govern this model. The first assumption is that the higher speed of the vehicle, the larger the gap between the vehicles (Indian Institute of Technology Bombay, 2014). The second assumption is that a safety distance between the two vehicles is to be maintained to avoid a collision. If $d x_{s a f e}$ is the safety distance then the gap $\Delta X_{n+1}^{t}$ between the $n$th and $(n+1)$ th can be calculated as (Indian Institute of Technology Bombay, 2014): 


$$
\Delta X_{n+1}^{t}=d x_{\text {safe }}+T *\left(V_{n+1}^{t}\right) \text {--------- } 1
$$

where $\Delta X_{n+1}^{t}$ is the difference between the position of vehicle $\mathrm{A}$ and vehicle $\mathrm{B}$ given as

$$
\Delta X_{n+1}^{t}=X_{n}^{t}-X_{n+1}^{t}
$$

Substituting $\Delta X_{n+1}^{t}$ in equation 1

$$
X_{n}^{t}-X_{n+1}^{t}=d x_{\text {safe }}+T *\left(V_{n+1}^{t}\right)
$$

By differentiating equation 3 with respect to time,

$$
V_{n}^{t}-V_{n+1}^{t}=T *\left(a_{n+1}^{t}\right) \text {--------- } 4
$$

Solving for $a_{n+1}$

$$
a_{n+1}^{t}=\frac{1}{T}\left(V_{n}^{t}-V_{n+1}^{t}\right) \text {-------- } 5
$$

As mentioned earlier, $\mathrm{T}$ is the sensitivity coefficient, which represent the lag time that the following vehicle takes to respond to the leader vehicle's changes. There are different formulas developed for the sensitivity coefficient, one of which is as follows

$$
\lambda=1 / \mathrm{T}=\alpha * \frac{V_{n+1}^{m}}{\left(X_{n}-X_{n+1}\right)^{l}}
$$

where $\mathrm{m}$ represents the speed exponent, 1 is the distance headway exponent and alpha is sensitivity coefficient. From equations 5 and 6, the acceleration of the following vehicle can be calculated as

$$
a_{n+1}^{t}=\alpha * \frac{V_{n+1}^{m}}{\left(X_{n}-X_{n+1}\right)^{l}}\left(V_{n}^{t}-V_{n+1}^{t}\right) \text {-------- } 7
$$

This equation is the core of car following model representing its foundation principle where the response of the following vehicle, $a_{n+1}^{t}$, is dependent on the stimulus which is a function of positions of the two vehicles, $X_{n}^{t}$ and $X_{n+1}^{t}$, along with the relative speeds $V_{n}^{t}-V_{n+1}^{t}$ and the speed of the following vehicle $V_{n+1}^{t}$. 
To the car following model, what is of importance however are the actions applying in each of the states a vehicle is in. A majority of car following models employ varied regimes in determining a follower's behavior (Olstam et al, 2004). Common setups employ three regimes including one for normal driving, another for free driving and another for emergency deceleration (Olstam et al, 2004). A vehicle is in the free regime if it is unconstrained and tries to achieve its desired speed. On the contrary, vehicles in the following regime accelerate with respect to the preceding vehicle in front. Lastly, a vehicle falling in the emergency deceleration regime reduces its speed in a bid to prevent the occurrence of a collision (Olstam et al, 2004).

\subsection{VISSIM Car Following Model}

VISSIM incorporate a car following model based on the psycho-physical driver behavior model suggested by Rainer Weidemann (PTV AG, 2011). The Wiedemann car following model was originally developed in 1974 and has been enhanced since then (Olstam et al, 2004). The model contains a psycho-physical car following model for longitudinal vehicle movement and a rule-based algorithm for lateral movements (PTV AG, 2011). The main idea of the Wiedemann car following model is the assumption that the vehicle can be in one of four different driving modes (PTV AG, 2011):

1- Free driving: In this driving mode there is no influence of the preceding vehicle. The driver has the freedom to drive at his desired speed or in other words, there is free flow driving condition.

2- Approaching: In this driving mode, the driver tries to adapt his own speed to the lower speed of the preceding vehicle.

3- Following: In this driving mode, the driver follows the preceding vehicle without 
any conscious acceleration or deceleration. This means that the driver would maintain approximately a constant safety distance to the preceding vehicle.

4- Braking: In this driving mode, when the distance of the preceding vehicle tends to fall below the desired safety distance or when the preceding vehicle change its speed suddenly the driver starts to decelerate at a medium to a high rates.

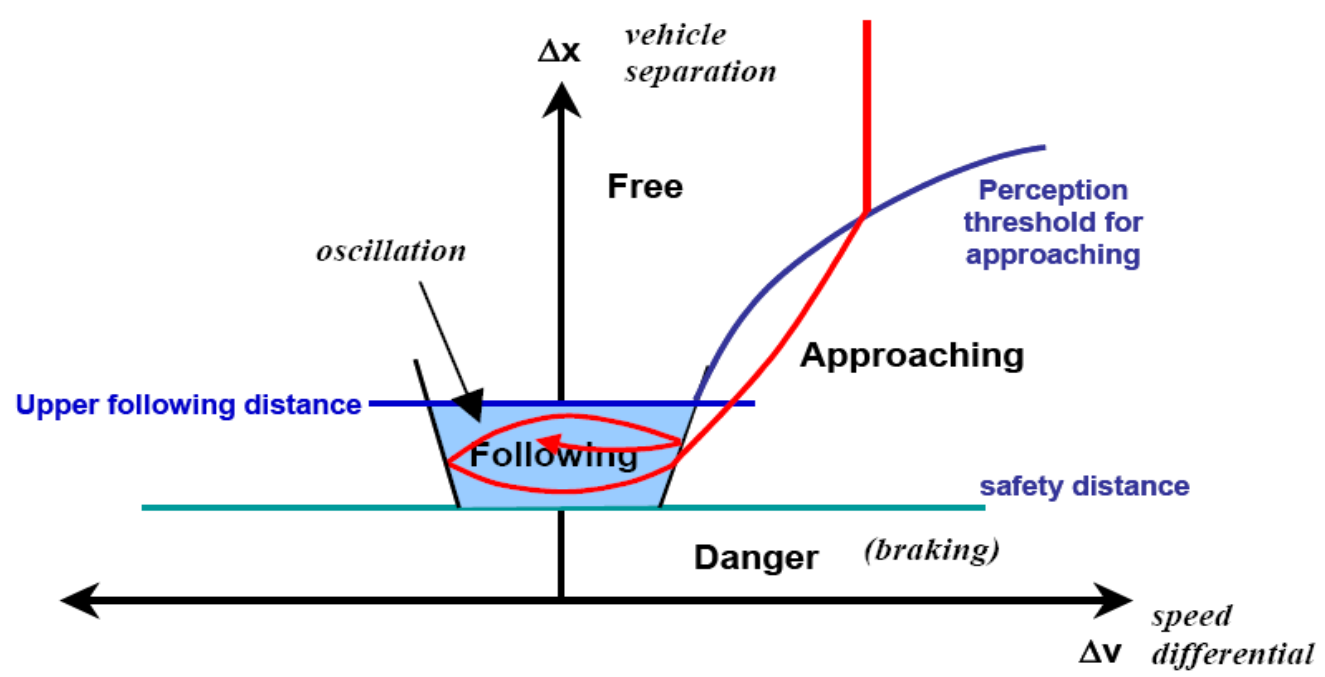

Figure 2: Weidemann car following model driving modes Source: VISSIM User Manual 4.10

The driver either accelerates or decelerates to change from one driving mode to other as soon as some threshold value expressed in terms of relative speed and distance is reached (Gao, 2008). The whole car following process is based on repetitive acceleration or deceleration of individual vehicles with drivers having different perceptions of speed difference, desired speed, and the safety distance between two successive vehicles (PTV AG, 2011).

VISSIM has three different driving models: Weidemann 1974 where it is mainly used for urban traffic, Weidemann 1999 where it is used for interurban traffic or motorway or freeway traffic, and lastly no interaction where vehicles do not recognize the other vehicles and it is mainly used for simplified pedestrian behavior (PTV AG, 
2011). For the purpose of this research the Weidemann 1999 model was only used.

\subsection{Weidemann 1999 Car Following Model}

The Wiedemann 99 car following model was developed in 1999 to render greater control of the car following characteristics for freeway modeling in VISSIM (PTV AG, 2011). The Wiedemann 99 model consists of ten calibration parameters, all labeled with a $\mathrm{CC}(\mathrm{CC}, \mathrm{CC} 1, \mathrm{CC} 3 \ldots \mathrm{CC} 9)$. Below are the descriptions of the $\mathrm{CC}$ parameters.

CCO is the standstill distance, and it is the distance that the driver wants to keep behind a stopped vehicle on the freeway. The default value is $4.92 \mathrm{ft}$.

CC1 is the headway time, and it is the desired time in seconds between the follower and the preceding vehicle. The higher the value is, the more careful the driver will be. The default value is $0.90 \mathrm{sec}$.

The safety distance is the minimum distance that the driver will keep behind the preceding vehicle, and at any given speed $\mathrm{v}$, it can be calculated to: $\mathrm{dx}_{-} \mathrm{safe}=\mathrm{CC} 0+$ $\mathrm{CC} 1 \cdot \mathrm{v}$. At high volumes of traffic, the safety distance will become the value with the greatest influence on capacity (PTV AG, 2011).

CC2 is the following variation, and it is the factor restricting the longitudinal oscillation of vehicles in the simulation. The longitudinal oscillation refers to the distance increment beyond the safety distance or how much more distance that the driver will allow between vehicles before the driver intentionally moves closer to the preceding vehicle. The default value is $13.12 \mathrm{ft}$.

CC3 is the threshold for entering "following" state, and it controls the start of the deceleration process when the driver recognizes that they are following a slower moving vehicle. It controls the time before reaching the safety distance that a driver begins to 
decelerate, not the rate at which the driver decelerates. The default value is $-8.00 \mathrm{sec}$.

CC4/CC5 are the negative and the positive following thresholds. They control the speed differences during the following state. Smaller values represent a more sensitive reaction of the driver to the acceleration or deceleration of the leading vehicle. CC4 is used for negative speed difference and CC5 is used for positive speed difference. The default values of CC4/CC5 are $-0.35 / 0.35 \mathrm{ft} / \mathrm{sec}$.

CC6 is the speed dependency of oscillation, and it controls the effect of distance on speed oscillation of the following vehicles. Increasing the value results in driver's speed oscillation as the distance between the follower and the leader increases. This means that the driver will accelerate and decelerate more often as the distance to the preceding vehicle grows. And if set to zero the speed oscillation is independent of the distance to the preceding vehicle. The default value is 11.44 .

CC7 is the oscillation acceleration, and it is the actual acceleration rate during the oscillation process. It controls whether the degree of speed oscillation is gentle and gradual or sudden and violent. The default value is $0.82 \mathrm{ft} / \mathrm{sec}^{\wedge} 2$.

CC8 is the standstill acceleration, and it is the desired acceleration when starting from a stopped position. The default value is $11.48 \mathrm{ft} / \mathrm{sec}^{\wedge} 2$.

CC9 is the acceleration at $50 \mathrm{mph}$, and it affects the acceleration behavior of the following vehicles when they are travelling at $50 \mathrm{mph}$. The default value is $4.92 \mathrm{ft} / \mathrm{sec}^{\wedge} 2$. 


\section{Chapter 4 RESEARCH METHODOLOGY AND RESULTS}

\subsection{Introduction}

The purpose of this research was to evaluate the impact that the autonomous vehicles have on the freeway capacity. This chapter discusses how the Weidemann 1999 parameters were calibrated to model the autonomous vehicles in VISSIM, and the network settings that were used to model both the realistic and the conceptual cases in VISSIM. Moreover, the results obtained from the simulations are presented in this chapter.

\subsection{Modeling Autonomous Vehicles in VISSIM}

The Weidemann 1999 calibration parameters control the drivers behavioral characteristics of a given vehicles model simulation. In order to model an autonomous vehicle in VISSIM, the ten parameters need to be calibrated or adjusted to model the characteristics of the autonomous vehicle. Four of the ten parameters are set to the default values, and the other six have been calibrated to properly model an autonomous vehicle.

The main idea behind an autonomous vehicle is shorter headway between two successive vehicles, which has to be anything less than 0.5 seconds (Bart et al, 2006). So $\mathrm{CC} 1$ parameter has been adjusted to 0.45 seconds to model autonomous vehicles with the default value being 0.90 seconds. CC2 has also been adjusted to 7.5 feet. As CC2 value gets smaller it makes the simulation drivers following behavior to be more aggressive. Which means that the drivers will be speeding up and slowing down at much higher frequency (Lownes et al, 2006). The autonomous vehicle can't be aggressive yet the following variation distance has to be shorter than it is for regular vehicles. So, CC2 
value has been adjusted very carefully to 7.5 feet to model the autonomous vehicles characteristics. Another characteristic of the autonomous vehicles is that they travel in a group or a convoy (Pinjari et al, 2013). The CC4 and the CC5 default values, which are $0.35 / 0.35 \mathrm{feet} /$ second result in fairly tight restriction of the following process. Smaller values will lead to more sensitive reaction of drivers to acceleration/deceleration of the preceding vehicle (Lownes et al, 2006). Which means that the vehicles will be more tightly coupled as they travel through the simulation. The values have been adjusted to 0.1/0.1 feet/second, which will make the vehicles travel in a convoy through the simulation. Moreover, it is recommended that CC4 and CC5 values to have the opposite sign and equal absolute values (PTV AG, 2003). As previously mentioned, increasing the CC6 value will make the driver's speed more as the distance between the follower and the leader increases. And to keep that distance constant through the simulation the CC6 value was increase from 11.44 to 15 so that it can model the autonomous vehicles. CC7 is the oscillation acceleration and it has been increased from $0.82 \mathrm{ft} / \mathrm{sec}^{\wedge} 2$ to $1.5 \mathrm{ft} / \mathrm{sec}^{\wedge} 2$. Increasing the value to more than $2 \mathrm{ft} / \mathrm{sec}^{\wedge} 2$ would make the vehicles speed oscillation very sudden and violent (Lownes et al, 2006), which are not the characteristics of the autonomous vehicles.

\subsection{VISSIM Modeling}

The study area boundary conditions play an important part in modeling and calibrating any freeway simulation in VISSIM, so careful considerations must be taken. For the purpose of this research two different study cases were modeled in VISSIM, a realistic case of I-79 section and a conceptual case. Moreover, the same cases were used to test the impact of various freeway lane configurations on efficiency of mixed traffic 
flow including regular and autonomous vehicles. To model the autonomous vehicles VISSIM the Wiedemann 99 car following model parameters of CC1, CC2, CC4/CC5, CC6 and $\mathrm{CC} 7$ were calibrated as mentioned in the above section.

Table 1: Weidemann 99 calibrated parameters modeling the autonomous vehicles in VISSIM

\begin{tabular}{|c|c|}
\hline Weidemann 99 Parameter & Calibrated Value \\
\hline CC1 & $0.45 \mathrm{sec}$ \\
\hline CC2 & $7.5 \mathrm{ft}$ \\
\hline CC4 & $-0.10 \mathrm{ft} / \mathrm{s}$ \\
\hline CC5 & $0.10 \mathrm{ft} / \mathrm{s}$ \\
\hline CC6 & 15 \\
\hline CC7 & $1.5 \mathrm{ft} / \mathrm{s}^{\wedge} 2$ \\
\hline
\end{tabular}

\subsubsection{Realistic Case}

A 6.5-miles two-lane section of I-79 was used to study the impact of the autonomous vehicles on freeway throughput. The network was modeled from the entrance of Chaplin Road to interstate 79 in West Virginia to the exit of Mount Morris in Pennsylvania. In addition to the 6.5-miles, 1,000 feet in the beginning and 1,000 feet at the end of the network were also used in the network modeling, but were removed while collecting the data for the purpose of this research. 


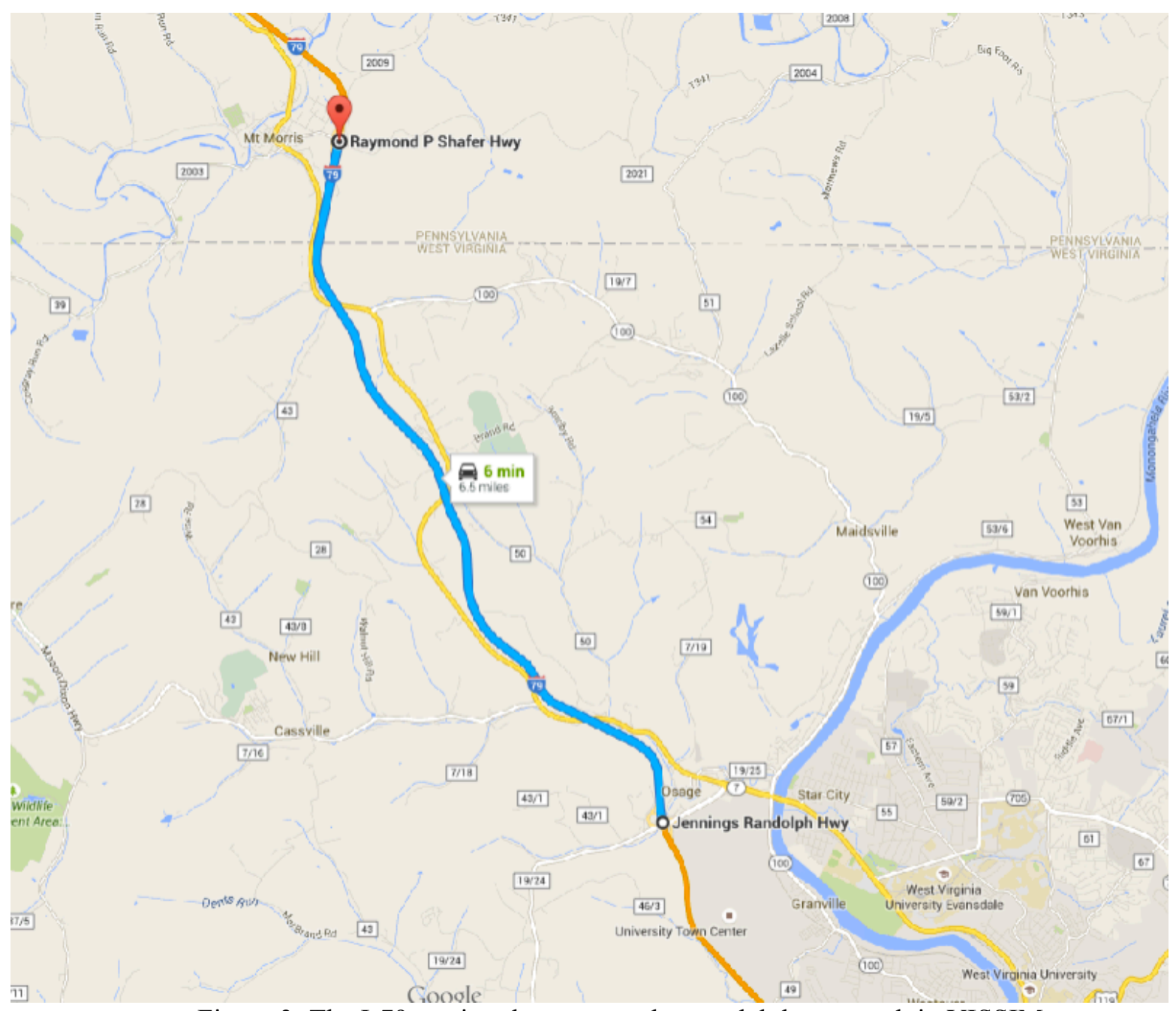

Figure 3: The I-79 section that was used to model the network in VISSIM Source: Google Maps 


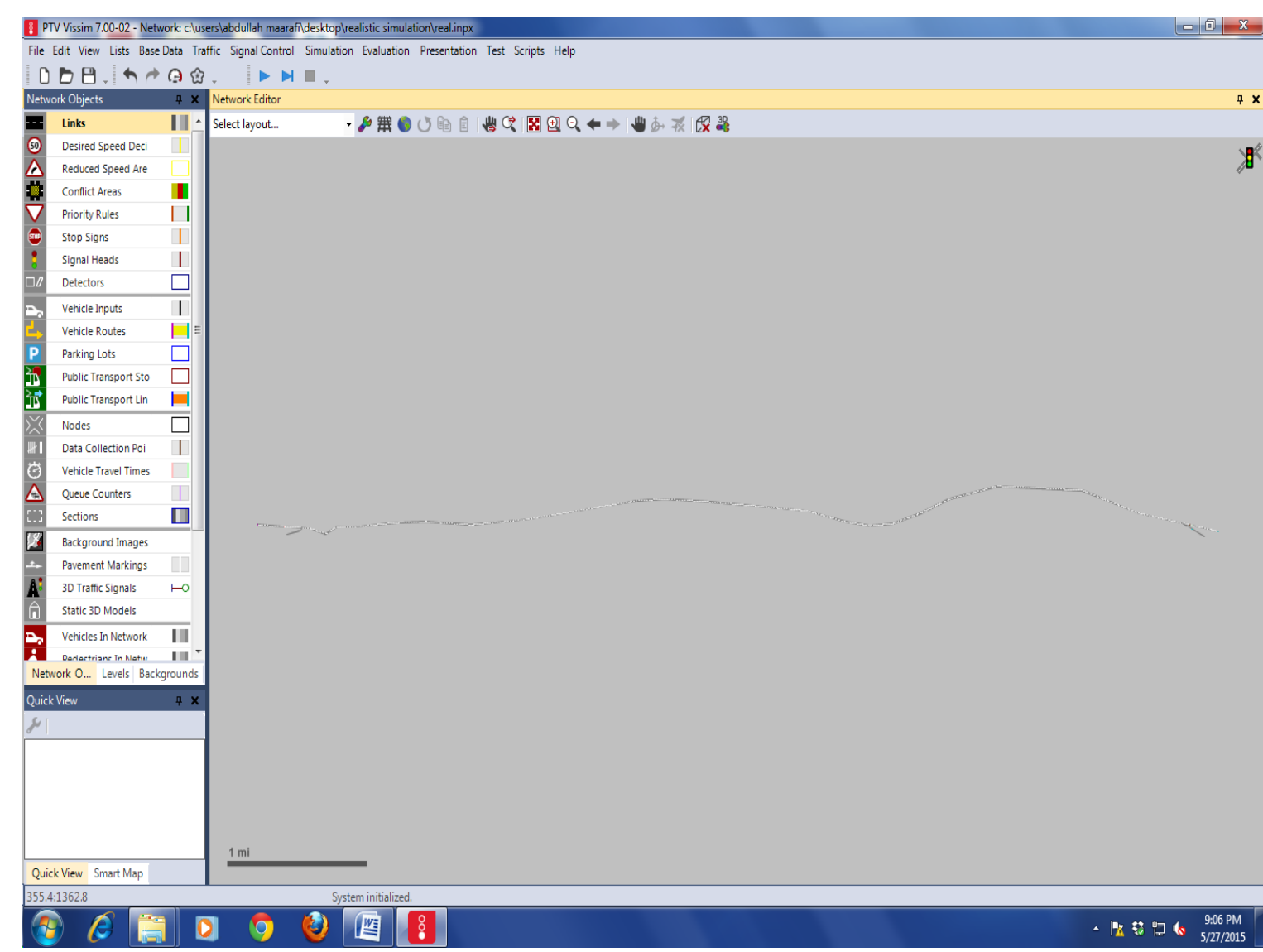

Figure 4: Snapshot of the realistic network in VISSIM

The speed limit was set to $70 \mathrm{mph}$, which is the original speed limit for that section of I-79. The simulation period was set to 5400 simulation seconds, which equals to 90 minutes. The first 15 minutes and the last 15 minutes were removed while collecting the data for the purpose of this research. A data collection point was placed at the end of each lane to collect the number of vehicles that traveled through the network and the speed of each of these vehicles. A travel time measurement was also placed to determine the time required by a vehicle between crossing the start and the destination of the network. The vehicle travel time measurement can also measure the delay for the traveling vehicles. The simulation time step was set to $10 \mathrm{steps} / \mathrm{second}$. It is a critical parameter associated with the car following model behavior in VISSIM surrounds the 
total number of time steps each second (Behrisch et al, 2011). During the simulation, each vehicle's position, speed and acceleration are computed at each time step. VISSIM permits for the user to select from the one to ten time steps every second. Enhanced time steps each second increasingly lead to more accurate outcomes of the simulation.

Five different models were created with seven different scenarios for each model. The models differ in the demand input volume. The first model demand volume was set to 2,400 vehicle/hour/lane. For the speed of $70 \mathrm{mph}$ and under ideal geometric and traffic conditions the demand volume for the freeway facilities is 2,400 vehicle/hour/lane (HCM, 2010). The second model input volume was set to 2,650 vehicle/hour/lane. The third model input volume was set to 2,900 vehicle/hour/lane. The fourth mode input volume was set to 3,150 vehicle/hour/lane. The fifth and the last model input volume was set to 3,400 vehicle/hour/lane. Each model has the same seven scenarios that were studied and used to determine the impact of the autonomous vehicles on freeway capacity.

- Scenario 1 consists of: All regular vehicles, which consist of $98 \%$ cars and $2 \%$ trucks. These are the default values in VISSIM.

- Scenario 2 consists of: $25 \%$ fleet mix of autonomous vehicles. This makes it to $73.5 \%$ regular cars, $24.5 \%$ autonomous vehicles, and the trucks remained the same at $2 \%$.

- Scenario 3 consists of: $40 \%$ fleet mix of autonomous vehicles. This makes it to $39.2 \%$ regular cars, $58.8 \%$ autonomous vehicles, and the trucks remained the same at $2 \%$. 
- Scenario 4 consists of: $50 \%$ fleet mix of autonomous vehicles. This makes it to $49 \%$ regular cars, $49 \%$ autonomous vehicles, and the trucks remained the same at $2 \%$.

- Scenario 5 consists of: $60 \%$ fleet mix of autonomous vehicles. This makes it to $39.2 \%$ regular cars, $58.8 \%$ autonomous vehicles, and the trucks remained the same at $2 \%$.

- Scenario 6 consists of: $75 \%$ fleet mix of autonomous vehicles. This makes it to $24.5 \%$ regular cars, $73.5 \%$ autonomous vehicles, and the trucks remained the same at $2 \%$.

- Scenario 7 consists of: No regular cars. This makes it to $98 \%$ autonomous vehicles and $2 \%$ trucks.

\subsubsection{Conceptual Case}

A 5-mile conceptual network was created with two exits and one entrance to study the impact of the autonomous vehicle on the freeway capacity. The first exit was placed at 4772 feet of the beginning of the modeled network, and the second exit was place at 6223 feet prior to the end of the network. The one entrance was placed in the middle of the modeled network. In addition to the 5-miles, 1,000 feet in the beginning and 1,000 feet at the end of the network were also used in the network modeling, but were removed while collecting the data for the purpose of this research. The conceptual network has the exact same settings as it is for the realistic case of I-79 such as: five models with seven scenario, data collection, travel time measurements, 5400 simulation seconds removing the first and last 15 minutes, and 10 steps/second. The speed limit was set to $65 \mathrm{mph}$. The first model demand volume was set to 2,350 vehicle/hour/lane. For the 
speed of $65 \mathrm{mph}$ and under ideal geometric and traffic conditions the demand volume for the freeway facilities is 2,350 vehicle/hour/lane (HCM, 2010). The second model input volume was set to 2,600 vehicle/hour/lane. The third model input volume was set to 2,850 vehicle/hour/lane. The forth mode input volume was set to 3,100 vehicle/hour/lane. The fifth and the last model input volume was set to 3,350 vehicle/hour/lane.

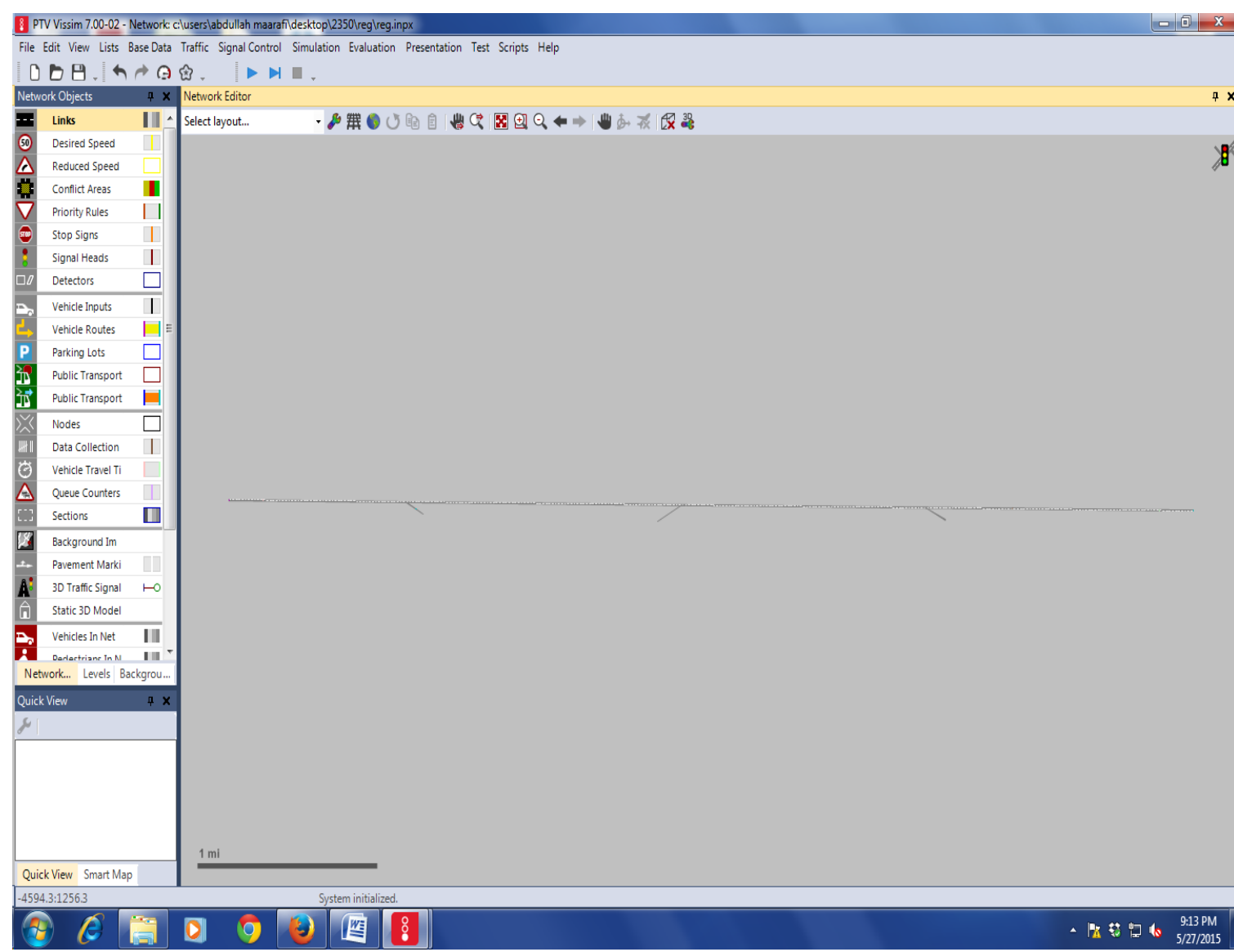

Figure 5: Snapshot of the conceptual network in VISSIM

\subsubsection{Realistic Case Lane Configuration}

The same exact realistic case settings was used to study the impact of various freeway lane configurations on efficiency of mixed traffic flow including regular and autonomous. Five different models with the same volume inputs as the previous realistic case were used to run the simulations. The $50 \%$ autonomous vehicles penetration rate 
was only used to test the impact of lane configuration on freeway capacity. Two different scenarios were used and studied to determine the impact of autonomous vehicles on freeway capacity. For the first scenario, autonomous vehicles were assigned to the left lane while the regular vehicles were assigned to the right lane. As for the second scenario, the autonomous vehicles were assigned to the right lane while the regular vehicles were assigned to the left lane.

\subsubsection{Conceptual Case Lane Configuration}

The same exact conceptual case settings were used to study the impact of various freeway lane configurations on efficiency of mixed traffic flow including regular and autonomous. Two scenarios of 50\% autonomous vehicles penetration rate were also used to study the impact of autonomous vehicles on freeway capacity. Both scenarios in the conceptual case lane configuration are similar to those used the realistic case lane configuration in section 4.3.3.

\subsection{Results}

The results for the realistic case are presented in table 2 through table 6 , and the results for the conceptual case are presented in table 7 through table 11 . The results for the realistic case lane configuration are presented in table 12 through table 16 , and the results for the conceptual case lane configuration are presented in table 17 though table 21. The values in the following tables are the average for the travel time, delay and speed collected from running the simulations and testing both cases with all the scenarios. In addition and most importantly, the throughput that corresponds to capacity is also collected for both of the cases with the different scenarios. 


\subsubsection{Realistic Case Results}

Table 2: Data summary for volume input of 2,400 vehicle/hour/lane with all 7 scenarios

\begin{tabular}{|c|c|c|c|c|c|}
\hline Vol.: 2400 & $\begin{array}{c}\text { Travel } \\
\text { Time (sec) }\end{array}$ & $\begin{array}{c}\text { Delay } \\
\text { (sec) }\end{array}$ & $\begin{array}{c}\text { Speed } \\
\text { (mph) }\end{array}$ & $\begin{array}{c}\text { Throughput } \\
\text { (vehicle/hour/lane) }\end{array}$ & $\begin{array}{c}\% \\
\text { Difference }\end{array}$ \\
\hline S1: Regular & 378.8002 & 29.82709 & 61.54727 & 2,238 & - \\
\hline S2: 25\% AV & 373.1475 & 24.07817 & 61.33753 & 2,240 & $0.0894 \%$ \\
\hline S3: 40\% AV & 405.7125 & 28.28892 & 56.87797 & 2,210 & $-1.251 \%$ \\
\hline S4: 50\% AV & 370.8707 & 21.56803 & 61.99802 & 2,242 & $0.179 \%$ \\
\hline S5: 60\% AV & 370.7071 & 21.70618 & 62.40322 & 2,243 & $0.223 \%$ \\
\hline S6: 75\% AV & 370.2352 & 21.11403 & 61.11481 & 2,248 & $0.447 \%$ \\
\hline S7: 100\% AV & 368.0573 & 18.95614 & 62.74085 & 2,243 & $0.223 \%$ \\
\hline
\end{tabular}

Table 3: Data summary for volume input of 2,650 vehicle/hour/lane with all 7 scenarios

\begin{tabular}{|c|c|c|c|c|c|}
\hline Vol.: 2650 & $\begin{array}{c}\text { Travel } \\
\text { Time (sec) }\end{array}$ & $\begin{array}{c}\text { Delay } \\
\text { (sec) }\end{array}$ & $\begin{array}{c}\text { Speed } \\
\text { (mph) }\end{array}$ & $\begin{array}{c}\text { Throughput } \\
\text { (vehicle/hour/lane) }\end{array}$ & $\begin{array}{c}\% \\
\text { Difference }\end{array}$ \\
\hline S1: Regular & 378.9846 & 30.0703 & 62.73983 & 2,287 & - \\
\hline S2: 25\% AV & 379.8561 & 30.87601 & 60.60184 & 2,453 & $7.258 \%$ \\
\hline S3: 40\% AV & 410.8513 & 33.49991 & 56.40193 & 2,456 & $7.390 \%$ \\
\hline S4: 50\% AV & 374.1929 & 24.96465 & 61.68767 & 2,465 & $7.783 \%$ \\
\hline S5: 60\% AV & 374.6383 & 25.69137 & 61.01839 & 2,465 & $7.783 \%$ \\
\hline S6: 75\% AV & 390.5708 & 41.59532 & 59.10241 & 2,476 & $8.264 \%$ \\
\hline S7: 100\% AV & 374.7459 & 25.74588 & 61.32846 & 2,476 & $8.264 \%$ \\
\hline
\end{tabular}

Table 4: Data summary for volume input of 2,900 vehicle/hour/lane with all 7 scenarios

\begin{tabular}{|c|c|c|c|c|c|}
\hline Vol.: 2900 & $\begin{array}{c}\text { Travel } \\
\text { Time (sec) }\end{array}$ & $\begin{array}{c}\text { Delay } \\
\text { (sec) }\end{array}$ & $\begin{array}{c}\text { Speed } \\
\text { (mph) }\end{array}$ & $\begin{array}{c}\text { Throughput } \\
\text { (vehicle/hour/lane) }\end{array}$ & $\begin{array}{c}\% \\
\text { Difference }\end{array}$ \\
\hline S1: Regular & 389.9355 & 41.01833 & 57.43557 & 2,273 & - \\
\hline S2: 25\% AV & 401.1315 & 52.17375 & 62.53682 & 2,423 & $6.599 \%$ \\
\hline S3: 40\% AV & 445.7342 & 68.47607 & 57.37179 & 2,568 & $12.978 \%$ \\
\hline S4: 50\% AV & 433.6359 & 64.63824 & 59.47386 & 2,619 & $15.222 \%$ \\
\hline S5: 60\% AV & 407.7287 & 58.98676 & 60.57008 & 2,667 & $17.334 \%$ \\
\hline S6: 75\% AV & 407.9794 & 58.66205 & 60.43998 & 2,674 & $17.642 \%$ \\
\hline S7: 100\% AV & 407.4044 & 58.5074 & 60.65816 & 2,687 & $18.214 \%$ \\
\hline
\end{tabular}

Table 5: Data summary for volume input of 3,150 vehicle/hour/lane with all 7 scenarios

\begin{tabular}{|c|c|c|c|c|c|}
\hline Vol.: 3150 & $\begin{array}{c}\text { Travel } \\
\text { Time (sec) }\end{array}$ & $\begin{array}{c}\text { Delay } \\
\text { (sec) }\end{array}$ & $\begin{array}{c}\text { Speed } \\
\text { (mph) }\end{array}$ & $\begin{array}{c}\text { Throughput } \\
\text { (vehicle/hour/lane) }\end{array}$ & $\begin{array}{c}\% \\
\text { Difference }\end{array}$ \\
\hline S1: Regular & 381.697 & 32.76965 & 62.55704 & 2,276 & - \\
\hline
\end{tabular}




\begin{tabular}{|c|c|c|c|c|c|}
\hline S2: 25\% AV & 398.0299 & 49.0542 & 58.77055 & 2,450 & $7.645 \%$ \\
\hline S3: 40\% AV & 470.368 & 93.17708 & 55.25555 & 2,561 & $12.252 \%$ \\
\hline S4: 50\% AV & 435.7168 & 86.72004 & 59.03161 & 2,613 & $14.807 \%$ \\
\hline S5: 60\% AV & 411.8816 & 63.11527 & 60.01592 & 2,667 & $17.179 \%$ \\
\hline S6: 75\% AV & 411.8053 & 63.06032 & 60.02485 & 2,680 & $17.750 \%$ \\
\hline S7: 100\% AV & 409.5822 & 62.96315 & 60.36522 & 2,692 & $18.278 \%$ \\
\hline
\end{tabular}

Table 6: Data summary for volume input of 3,400 vehicle/hour/lane with all 7 scenarios

\begin{tabular}{|c|c|c|c|c|c|}
\hline Vol.: 3400 & $\begin{array}{c}\text { Travel } \\
\text { Time (sec) }\end{array}$ & $\begin{array}{c}\text { Delay } \\
\text { (sec) }\end{array}$ & $\begin{array}{c}\text { Speed } \\
\text { (mph) }\end{array}$ & $\begin{array}{c}\text { Throughput } \\
\text { (vehicle/hour/lane) }\end{array}$ & $\begin{array}{c}\% \\
\text { Difference }\end{array}$ \\
\hline S1: Regular & 377.0129 & 28.1334 & 62.46418 & 2,274 & - \\
\hline S2: 25\% AV & 400.9675 & 51.98329 & 59.16705 & 2,464 & $8.355 \%$ \\
\hline S3: 40\% AV & 430.5861 & 53.32568 & 56.71817 & 2,560 & $12.577 \%$ \\
\hline S4: 50\% AV & 426.0056 & 52.0436 & 58.45639 & 2,613 & $14.908 \%$ \\
\hline S5: 60\% AV & 418.0497 & 52.3354 & 59.8132 & 2,658 & $16.887 \%$ \\
\hline S6: 75\% AV & 411.4358 & 62.50849 & 60.06546 & 2,671 & $17.458 \%$ \\
\hline S7: 100\% AV & 410.9006 & 62.48632 & 60.8684 & 2,685 & $18.074 \%$ \\
\hline
\end{tabular}

\subsubsection{Conceptual Case Results}

Table 7: Data summary for volume input of 2,350 vehicle/hour/lane with all 7 scenarios

\begin{tabular}{|c|c|c|c|c|c|}
\hline Vol.: 2350 & $\begin{array}{c}\text { Travel } \\
\text { Time (sec) }\end{array}$ & $\begin{array}{c}\text { Delay } \\
\text { (sec) }\end{array}$ & $\begin{array}{c}\text { Speed } \\
\text { (mph) }\end{array}$ & $\begin{array}{c}\text { Throughput } \\
\text { (vehicle/hour/lane) }\end{array}$ & $\begin{array}{c}\text { \% } \\
\text { Difference }\end{array}$ \\
\hline S1: Regular & 312.2049 & 22.30169 & 57.85408 & 2,265 & - \\
\hline S2: 25\% AV & 310.3573 & 20.31174 & 58.01607 & 2,252 & $-0.00441 \%$ \\
\hline S3: 40\% AV & 333.4312 & 21.19335 & 58.40717 & 2,257 & $-0.00353 \%$ \\
\hline S4: 50\% AV & 309.1786 & 19.05278 & 58.3491 & 2,262 & $-0.00132 \%$ \\
\hline S5: 60\% AV & 308.2088 & 18.06533 & 58.36361 & 2,262 & $-0.00132 \%$ \\
\hline S6: 75\% AV & 307.5999 & 17.24557 & 58.78901 & 2,269 & $0.00177 \%$ \\
\hline S7: 100\% AV & 305.447 & 15.19158 & 58.99168 & 2,278 & $0.00574 \%$ \\
\hline
\end{tabular}

Table 8: Data summary for volume input of 2,600 vehicle/hour/lane with all 7 scenarios

\begin{tabular}{|c|c|c|c|c|c|}
\hline Vol.: 2600 & $\begin{array}{c}\text { Travel } \\
\text { Time (sec) }\end{array}$ & $\begin{array}{c}\text { Delay } \\
\text { (sec) }\end{array}$ & $\begin{array}{c}\text { Speed } \\
\text { (mph) }\end{array}$ & $\begin{array}{c}\text { Throughput } \\
\text { (vehicle/hour/lane) }\end{array}$ & $\begin{array}{c}\% \\
\text { Difference }\end{array}$ \\
\hline S1: Regular & 314.9625 & 25.08728 & 58.01247 & 2,346 & - \\
\hline S2: 25\% AV & 318.9305 & 28.93727 & 57.94473 & 2,485 & $5.925 \%$ \\
\hline S3: 40\% AV & 337.0072 & 24.82862 & 57.99275 & 2,489 & $6.095 \%$ \\
\hline S4: 50\% AV & 312.1917 & 22.098 & 58.11109 & 2,495 & $6.351 \%$ \\
\hline S5: 60\% AV & 310.0527 & 19.91746 & 58.28781 & 2,507 & $6.863 \%$ \\
\hline S6: 75\% AV & 311.2409 & 20.93656 & 58.08754 & 2,508 & $6.905 \%$ \\
\hline S7: 100\% AV & 308.7456 & 18.55301 & 58.39123 & 2,528 & $7.758 \%$ \\
\hline
\end{tabular}


Table 9: Data summary for volume input of 2,850 vehicle/hour/lane with all 7 scenarios

\begin{tabular}{|c|c|c|c|c|c|}
\hline Vol.: 2850 & $\begin{array}{c}\text { Travel } \\
\text { Time (sec) }\end{array}$ & $\begin{array}{c}\text { Delay } \\
\text { (sec) }\end{array}$ & $\begin{array}{c}\text { Speed } \\
\text { (mph) }\end{array}$ & $\begin{array}{c}\text { Throughput } \\
\text { (vehicle/hour/lane) }\end{array}$ & $\begin{array}{c}\% \\
\text { Difference }\end{array}$ \\
\hline S1: Regular & 317.7579 & 27.88543 & 57.69839 & 2,346 & - \\
\hline S2: 25\% AV & 328.2394 & 38.27701 & 57.81723 & 2,568 & $9.463 \%$ \\
\hline S3: 40\% AV & 353.0222 & 40.96504 & 57.72883 & 2,677 & $14.109 \%$ \\
\hline S4: 50\% AV & 324.6508 & 34.68627 & 57.93268 & 2,716 & $15.772 \%$ \\
\hline S5: 60\% AV & 316.6215 & 26.60694 & 58.03044 & 2,717 & $15.814 \%$ \\
\hline S6: 75\% AV & 313.6428 & 23.41928 & 57.43747 & 2,723 & $16.070 \%$ \\
\hline S7: 100\% AV & 313.1223 & 23.3804 & 58.66082 & 2,732 & $16.454 \%$ \\
\hline
\end{tabular}

Table 10: Data summary for volume input of 3,100 vehicle/hour/lane with all 7 scenarios

\begin{tabular}{|c|c|c|c|c|c|}
\hline Vol.: 3100 & $\begin{array}{c}\text { Travel } \\
\text { Time (sec) }\end{array}$ & $\begin{array}{c}\text { Delay } \\
\text { (sec) }\end{array}$ & $\begin{array}{c}\text { Speed } \\
\text { (mph) }\end{array}$ & $\begin{array}{c}\text { Throughput } \\
\text { (vehicle/hour/lane) }\end{array}$ & $\begin{array}{c}\text { \% } \\
\text { Difference }\end{array}$ \\
\hline S1: Regular & 314.7744 & 24.88805 & 57.75587 & 2,349 & - \\
\hline S2: 25\% AV & 321.3922 & 31.41799 & 57.84295 & 2,604 & $10.857 \%$ \\
\hline S3: 40\% AV & 366.9929 & 54.92169 & 57.89061 & 2,660 & $13.240 \%$ \\
\hline S4: 50\% AV & 355.9043 & 54.04111 & 57.97 & 2,764 & $17.667 \%$ \\
\hline S5: 60\% AV & 350.1936 & 53.24286 & 58.22393 & 2,769 & $17.880 \%$ \\
\hline S6: 75\% AV & 348.803 & 52.64237 & 58.42882 & 2,776 & $18.178 \%$ \\
\hline S7: 100\% AV & 348.2716 & 52.14355 & 58.14013 & 2,786 & $18.604 \%$ \\
\hline
\end{tabular}

Table 11: Data summary for volume input of 3,350 vehicle/hour/lane with all 7 scenarios

\begin{tabular}{|c|c|c|c|c|c|}
\hline Vol.: 3350 & $\begin{array}{c}\text { Travel } \\
\text { Time (sec) }\end{array}$ & $\begin{array}{c}\text { Delay } \\
\text { (sec) }\end{array}$ & $\begin{array}{c}\text { Speed } \\
\text { (mph) }\end{array}$ & $\begin{array}{c}\text { Throughput } \\
\text { (vehicle/hour/lane) }\end{array}$ & $\begin{array}{c}\text { \% } \\
\text { Difference }\end{array}$ \\
\hline S1: Regular & 313.9848 & 24.09203 & 57.86306 & 2,347 & - \\
\hline S2: 25\% AV & 334.9789 & 45.01761 & 57.80774 & 2,548 & $8.564 \%$ \\
\hline S3: 40\% AV & 367.259 & 55.24698 & 57.6864 & 2,715 & $15.680 \%$ \\
\hline S4: 50\% AV & 326.1995 & 36.29569 & 57.90429 & 2,794 & $19.046 \%$ \\
\hline S5: 60\% AV & 324.1146 & 34.20596 & 57.90406 & 2,867 & $22.156 \%$ \\
\hline S6: 75\% AV & 322.1326 & 34.03084 & 58.40295 & 2,874 & $22.540 \%$ \\
\hline S7: 100\% AV & 321.9299 & 33.7891 & 58.77326 & 2,886 & $22.965 \%$ \\
\hline
\end{tabular}

\subsubsection{Realistic Case Lane Configuration Results}

Table 12: Data summary for volume input of 2,400 vehicle/hour/lane

\begin{tabular}{|c|c|c|c|c|c|}
\hline Vol.: 2400 & $\begin{array}{c}\text { Travel } \\
\text { Time (sec) }\end{array}$ & $\begin{array}{c}\text { Delay } \\
\text { (sec) }\end{array}$ & $\begin{array}{c}\text { Speed } \\
(\mathrm{mph})\end{array}$ & $\begin{array}{c}\text { Throughput } \\
\text { (vehicle/hour/lane) }\end{array}$ & $\begin{array}{c}\% \\
\text { Difference }\end{array}$ \\
\hline
\end{tabular}




\begin{tabular}{|c|c|c|c|c|c|}
\hline S4: 50\% AV & 378.8708 & 21.56803 & 61.99802 & 2,242 & - \\
\hline Scenario 1 & 571.9514 & 223.1876 & 60.06518 & 2,143 & $-4.416 \%$ \\
\hline Scenario 2 & 718.6367 & 369.6713 & 55.81419 & 1,880 & $-16.146 \%$ \\
\hline
\end{tabular}

Table 13: Data summary for volume input of 2,650 vehicle/hour/lane

\begin{tabular}{|c|c|c|c|c|c|}
\hline Vol.: 2650 & $\begin{array}{c}\text { Travel } \\
\text { Time (sec) }\end{array}$ & $\begin{array}{c}\text { Delay } \\
\text { (sec) }\end{array}$ & $\begin{array}{c}\text { Speed } \\
\text { (mph) }\end{array}$ & $\begin{array}{c}\text { Throughput } \\
\text { (vehicle/hour/lane) }\end{array}$ & $\begin{array}{c}\% \\
\text { Difference }\end{array}$ \\
\hline S4: 50\% AV & 374.1929 & 24.96465 & 61.68767 & 2,465 & - \\
\hline Scenario 1 & 582.9719 & 234.1473 & 60.05938 & 2,143 & $-13.063 \%$ \\
\hline Scenario 2 & 709.6782 & 361.1271 & 55.22041 & 1,984 & $-19.513 \%$ \\
\hline
\end{tabular}

Table 14: Data summary for volume input of 2,900 vehicle/hour/lane

\begin{tabular}{|c|c|c|c|c|c|}
\hline Vol.: 2900 & $\begin{array}{c}\text { Travel } \\
\text { Time (sec) }\end{array}$ & $\begin{array}{c}\text { Delay } \\
\text { (sec) }\end{array}$ & $\begin{array}{c}\text { Speed } \\
\text { (mph) }\end{array}$ & $\begin{array}{c}\text { Throughput } \\
\text { (vehicle/hour/lane) }\end{array}$ & $\begin{array}{c}\% \\
\text { Difference }\end{array}$ \\
\hline S4: 50\% AV & 433.6359 & 64.63824 & 59.47386 & 2,619 & - \\
\hline Scenario 1 & 532.5962 & 183.9438 & 60.22825 & 2,172 & $-17.068 \%$ \\
\hline Scenario 2 & 758.0436 & 381.0662 & 51.46429 & 1,908 & $-27.148 \%$ \\
\hline
\end{tabular}

Table 15: Data summary for volume input of 3,150 vehicle/hour/lane

\begin{tabular}{|c|c|c|c|c|c|}
\hline Vol.: 3150 & $\begin{array}{c}\text { Travel } \\
\text { Time (sec) }\end{array}$ & $\begin{array}{c}\text { Delay } \\
\text { (sec) }\end{array}$ & $\begin{array}{c}\text { Speed } \\
\text { (mph) }\end{array}$ & $\begin{array}{c}\text { Throughput } \\
\text { (vehicle/hour/lane) }\end{array}$ & $\begin{array}{c}\% \\
\text { Difference }\end{array}$ \\
\hline S4: 50\% AV & 435.7168 & 86.72004 & 59.03161 & 2,613 & - \\
\hline Scenario 1 & 526.9514 & 178.0584 & 60.43968 & 2,169 & $-16.992 \%$ \\
\hline Scenario 2 & 692.3424 & 343.8343 & 55.1279 & 1,998 & $-23.536 \%$ \\
\hline
\end{tabular}

Table 16: Data summary for volume input of 3,400 vehicle/hour/lane

\begin{tabular}{|c|c|c|c|c|c|}
\hline Vol.: 3400 & $\begin{array}{c}\text { Travel } \\
\text { Time (sec) }\end{array}$ & $\begin{array}{c}\text { Delay } \\
\text { (sec) }\end{array}$ & $\begin{array}{c}\text { Speed } \\
\text { (mph) }\end{array}$ & $\begin{array}{c}\text { Throughput } \\
\text { (vehicle/hour/lane) }\end{array}$ & $\begin{array}{c}\text { \% } \\
\text { Difference }\end{array}$ \\
\hline S4: 50\% AV & 426.0056 & 52.0436 & 58.45639 & 2,613 & - \\
\hline Scenario 1 & 524.1078 & 175.3922 & 60.16367 & 2,171 & $-16.915 \%$ \\
\hline Scenario 2 & 742.9737 & 366.0098 & 52.21041 & 1,975 & $-24.416 \%$ \\
\hline
\end{tabular}

\subsubsection{Conceptual Case Lane Configuration Results}

Table 17: Data summary for volume input of 2,350 vehicle/hour/lane

\begin{tabular}{|c|c|c|c|c|c|}
\hline Vol.: 2350 & $\begin{array}{c}\text { Travel } \\
\text { Time (sec) }\end{array}$ & $\begin{array}{c}\text { Delay } \\
\text { (sec) }\end{array}$ & $\begin{array}{c}\text { Speed } \\
\text { (mph) }\end{array}$ & $\begin{array}{c}\text { Throughput } \\
\text { (vehicle/hour/lane) }\end{array}$ & $\begin{array}{c}\% \\
\text { Difference }\end{array}$ \\
\hline S4: 50\% AV & 309.1786 & 19.05278 & 58.3491 & 2,262 & - \\
\hline
\end{tabular}




\begin{tabular}{|l|l|l|l|l|l|}
\hline Scenario 1 & 430.9838 & 141.1452 & 57.22265 & 2,015 & $-10.920 \%$ \\
\hline Scenario 2 & 417.3755 & 105.5496 & 57.23272 & 1,638 & $-27.586 \%$ \\
\hline
\end{tabular}

Table 18: Data summary for volume input of 2,600 vehicle/hour/lane

\begin{tabular}{|c|c|c|c|c|c|}
\hline Vol.: 2600 & $\begin{array}{c}\text { Travel } \\
\text { Time (sec) }\end{array}$ & $\begin{array}{c}\text { Delay } \\
\text { (sec) }\end{array}$ & $\begin{array}{c}\text { Speed } \\
\text { (mph) }\end{array}$ & $\begin{array}{c}\text { Throughput } \\
\text { (vehicle/hour/lane) }\end{array}$ & $\begin{array}{c}\% \\
\text { Difference }\end{array}$ \\
\hline S4: 50\% AV & 312.1917 & 22.098 & 58.11109 & 2,495 & - \\
\hline Scenario 1 & 423.8555 & 134.037 & 57.76504 & 1,942 & $-22.164 \%$ \\
\hline Scenario 2 & 481.6018 & 191.8287 & 57.38487 & 1,831 & $-26.613 \%$ \\
\hline
\end{tabular}

Table 19: Data summary for volume input of 2,850 vehicle/hour/lane

\begin{tabular}{|c|c|c|c|c|c|}
\hline Vol.: 2850 & $\begin{array}{c}\text { Travel } \\
\text { Time (sec) }\end{array}$ & $\begin{array}{c}\text { Delay } \\
\text { (sec) }\end{array}$ & $\begin{array}{c}\text { Speed } \\
\text { (mph) }\end{array}$ & $\begin{array}{c}\text { Throughput } \\
\text { (vehicle/hour/lane) }\end{array}$ & $\begin{array}{c}\% \\
\text { Difference }\end{array}$ \\
\hline S4: 50\% AV & 324.6508 & 34.68627 & 57.93268 & 2,716 & - \\
\hline Scenario 1 & 432.5021 & 142.6706 & 56.95163 & 1,964 & $-27.688 \%$ \\
\hline Scenario 2 & 405.5098 & 93.64684 & 57.05457 & 1,659 & $--38.918 \%$ \\
\hline
\end{tabular}

Table 20: Data summary for volume input of 3,100 vehicle/hour/lane

\begin{tabular}{|c|c|c|c|c|c|}
\hline Vol.: 3100 & $\begin{array}{c}\text { Travel } \\
\text { Time (sec) }\end{array}$ & $\begin{array}{c}\text { Delay } \\
\text { (sec) }\end{array}$ & $\begin{array}{c}\text { Speed } \\
\text { (mph) }\end{array}$ & $\begin{array}{c}\text { Throughput } \\
\text { (vehicle/hour/lane) }\end{array}$ & $\begin{array}{c}\% \\
\text { Difference }\end{array}$ \\
\hline S4: 50\% AV & 355.9043 & 54.04111 & 57.97 & 2,764 & - \\
\hline Scenario 1 & 396.8012 & 106.9005 & 57.454 & 1,998 & $-27.713 \%$ \\
\hline Scenario 2 & 314.0728 & 123.2984 & 57.16439 & 1,870 & $-32.344 \%$ \\
\hline
\end{tabular}

Table 21: Data summary for volume input of 3,350 vehicle/hour/lane

\begin{tabular}{|c|c|c|c|c|c|}
\hline Vol.: 3350 & $\begin{array}{c}\text { Travel } \\
\text { Time (sec) }\end{array}$ & $\begin{array}{c}\text { Delay } \\
\text { (sec) }\end{array}$ & $\begin{array}{c}\text { Speed } \\
\text { (mph) }\end{array}$ & $\begin{array}{c}\text { Throughput } \\
\text { (vehicle/hour/lane) }\end{array}$ & $\begin{array}{c}\% \\
\text { Difference }\end{array}$ \\
\hline S4: 50\% AV & 326.1995 & 36.29569 & 57.90429 & 2,794 & - \\
\hline Scenario 1 & 422.5203 & 132.6676 & 57.09162 & 2,086 & $-25.340 \%$ \\
\hline Scenario 2 & 413.7158 & 123.9311 & 57.13496 & 1,828 & $-34.574 \%$ \\
\hline
\end{tabular}

\subsection{Analysis}

The subjects being evaluated in this thesis consist of: travel time, delay, speed and most importantly the difference in freeway throughput. For section 4.5.1 and section 4.5.2, the results are being compared to the first scenario of all regular vehicles. For 
section 4.5.3 and section 4.5.4, the results are being compared to the $50 \%$ penetration rate scenario without the lane configuration assignments.

\subsubsection{Realistic Case Analysis}

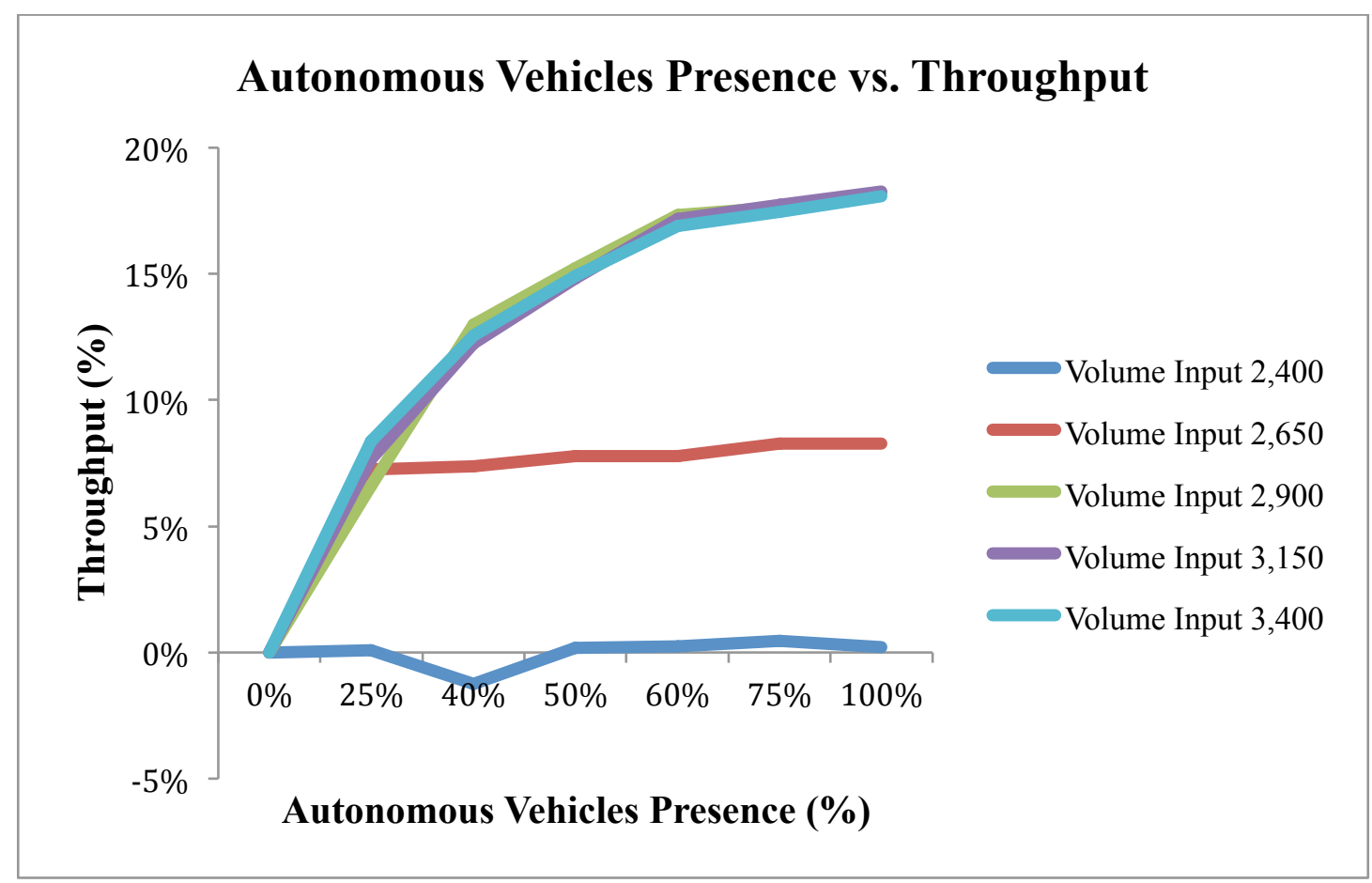

Figure 6: Comparison of throughput with respect to different autonomous vehicles presence at different volume inputs

Figure 6 shows the freeway throughput with respect to different autonomous vehicles presence at five different input volumes. For the volume input of 2,400 vehicle/hour/lane, the autonomous vehicles have shown no impact on freeway throughput.

As for the input volume of 2,650 vehicle/hour/lane, the autonomous vehicles have shown an impact on freeway throughput that ranges between $7-8 \%$ as we hit $25 \%$ of autonomous vehicles presence, then remains constant throughout different autonomous vehicles penetration rate. These results agree with what Bierstedt et al. (2014) have 
mentioned that freeway throughput is expected to increase when the presence of autonomous vehicles are at $25-35 \%$ of the fleet mix.

As for the rest of the volume inputs, freeway throughput increases at a high rate until we reach $40 \%$ of penetration rate, then it continues to increase but at a slower rate. Despite the lower rate of increase, positive impacts on the freeway throughput start to be noticeable when the autonomous vehicles exceed $40 \%$ penetration rate (Jones and Philips, 2013). Moreover, Davis (2005) has found that with the 50\% penetration rate of autonomous vehicles, freeway throughput is expected to increase to more than $7 \%$. Figure 6 shows that the highest change in freeway throughput is $18.278 \%$ obtained at volume input of 3,150 vehicle/hour/rate at 100\% autonomous vehicles presence.

\subsubsection{Conceptual Case Analysis}

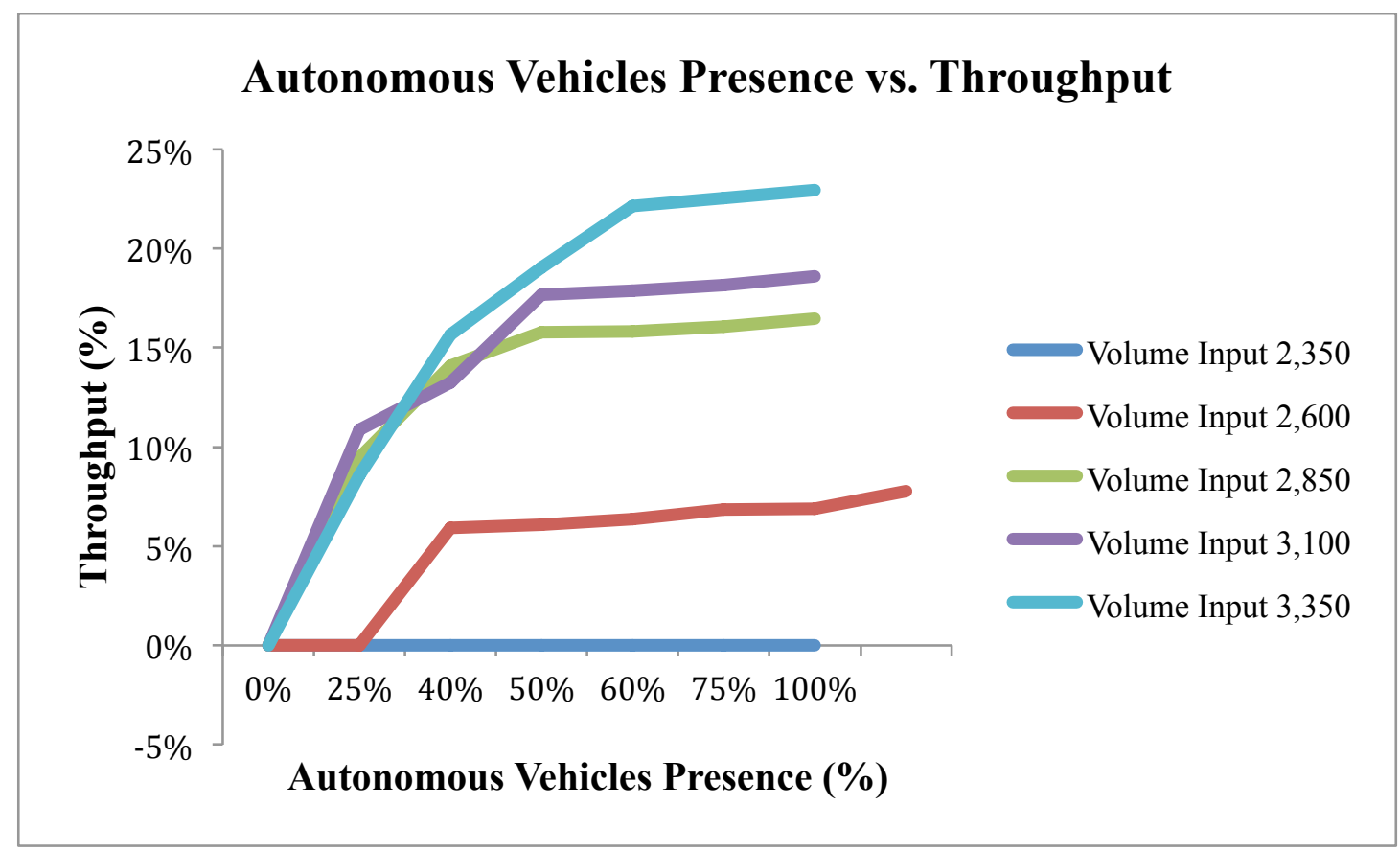

Figure 7: Comparison of throughput with respect to different autonomous vehicles presence at different volume inputs 
Figure 7 shows the freeway throughput with respect to different autonomous vehicles presence at five different input volumes. For the volume input of 2,350 vehicle/hour/lane, the autonomous vehicles have shown no impact on freeway throughput.

For the volume input of 2,600 vehicle/hour/lane, autonomous vehicles have shown an impact of freeway throughput as the autonomous vehicles presence hit $25 \%$. The impact continues to increase at a steady rate after that until it reaches $7.758 \%$ when the presence of autonomous vehicles is at 100\%. Based on the study by Reich (2013), freeway throughput will increase and that is when there is about $20-40 \%$ vehicle fleet penetration of autonomous vehicles. This agrees with the results that were found in the 2,600 vehicle/hour/lane input volume.

As for the volume input of 2,850 vehicle/hour/lane and the volume input of 3,100 vehicle/hour/lane, the freeway throughput increases by $13-14 \%$ when the autonomous vehicles penetration rate is at $40 \%$. Then the capacity increases even higher to $16-18 \%$ when the autonomous vehicles penetration rate is at $100 \%$. Based on Tientrakool et al. (2011) study, freeway throughput increases slowly when the penetration rate is at $30 \%$ or less, then it starts increasing as the penetration rate of autonomous vehicles gets higher, and this is exactly what was found with the input volume of 2,850 vehicle/hour/lane and the 3,100 vehicle/hour/lane. Moreover, Van Arem et al. (2006) research states that the increase in freeway throughput will be noticeable when the autonomous vehicles penetration rate is at $40 \%$ or higher.

For the volume input of 3,350 vehicles/hour/lane, autonomous vehicles have shown a very significant impact on freeway throughput. In fact, it has shown the highest 
increase in all the volume inputs in both the conceptual and the realistic cases. Figure 7

shows that the freeway throughput has increased by up to $22.965 \%$ for this input volume.

\subsubsection{Realistic Case Lane Configuration Analysis}

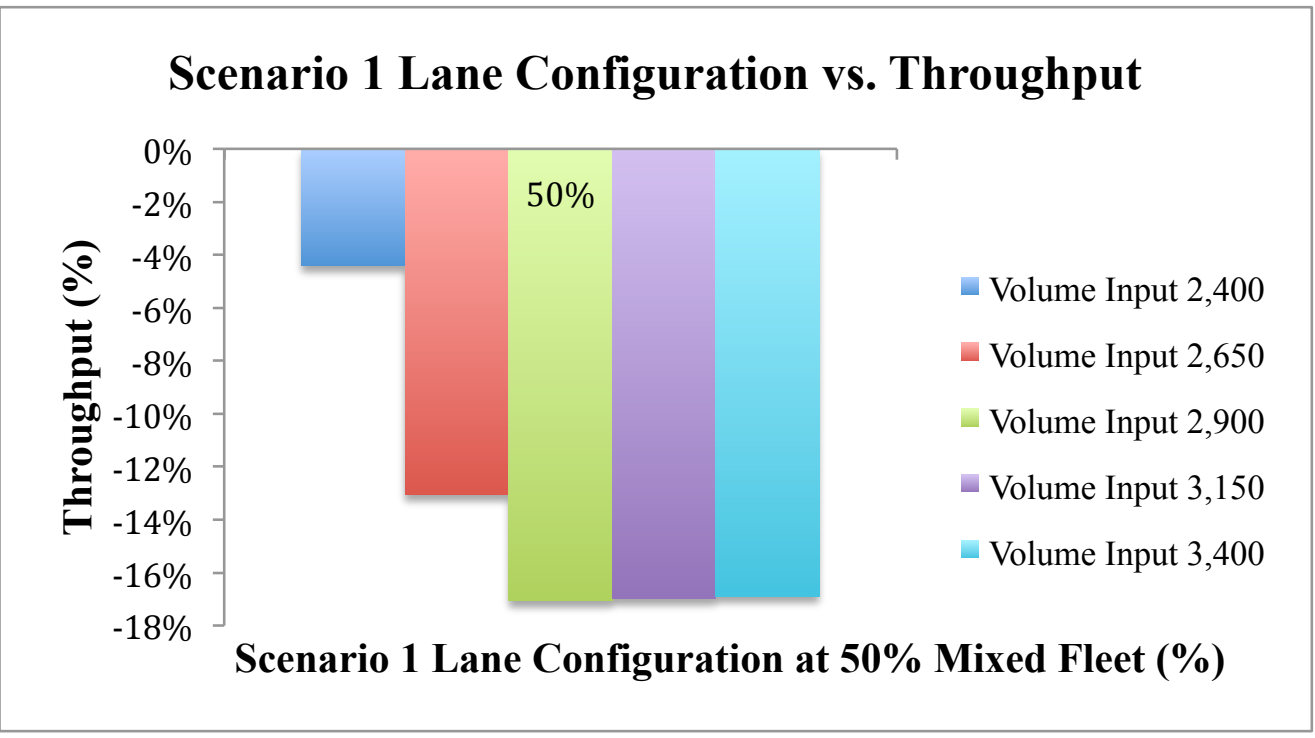

Figure 8: Scenario 1 of the lane configuration for $50 \%$ fleet mix

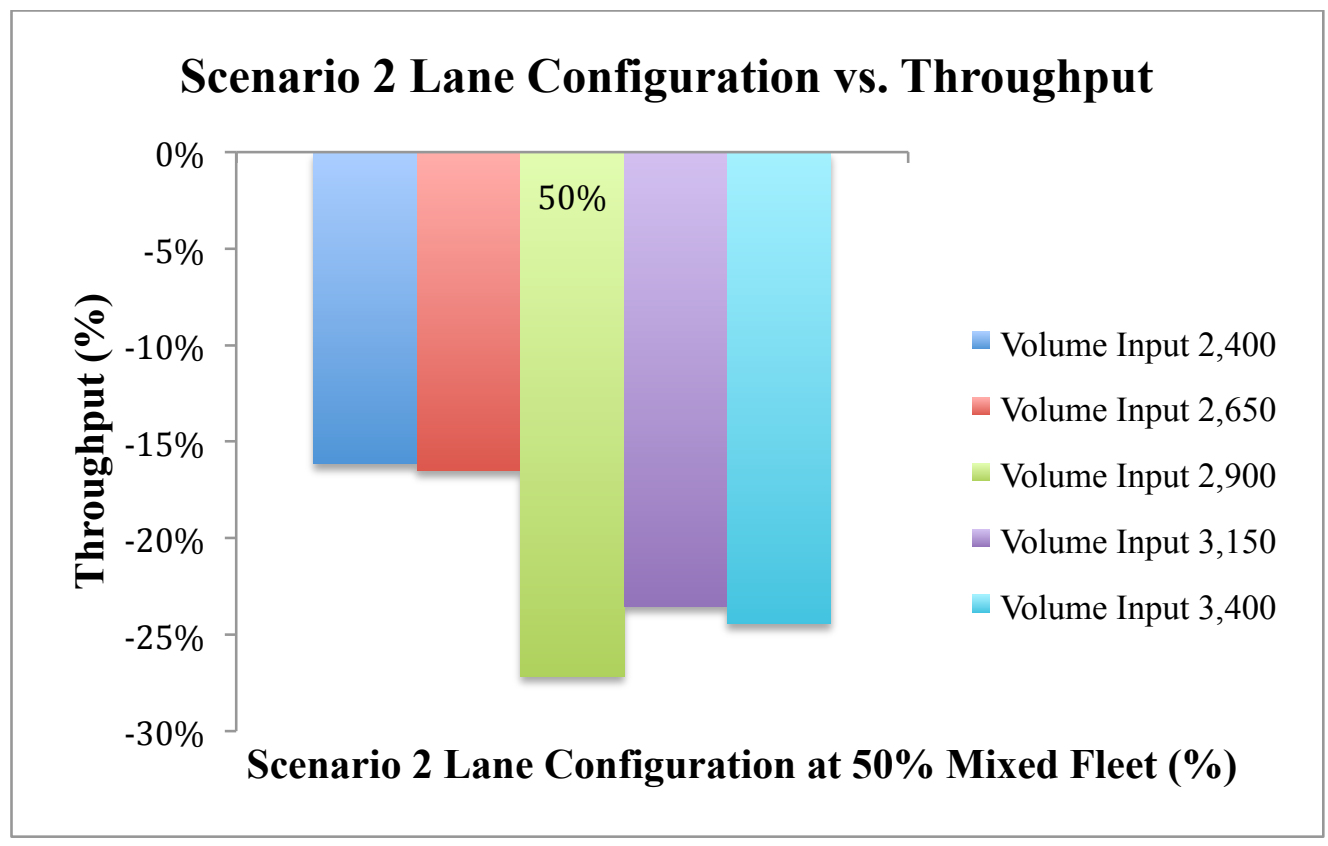

Figure 9: Scenario 2 of the lane configuration for $50 \%$ fleet mix 
Figure 8 and figure 9 show the impact of various freeway lane configuration on efficiency of mixed traffic flow including regular and autonomous vehicles. When compared to the $50 \%$ mixed fleet of free lane changing, both scenarios have shown a negative impact on the freeway throughput and that is due to the congestion caused by lanes with regular vehicles. In addition, travel time and delay have increased tremendously while the speed has decreased as well.

\subsubsection{Conceptual Case Lane Configuration Analysis}

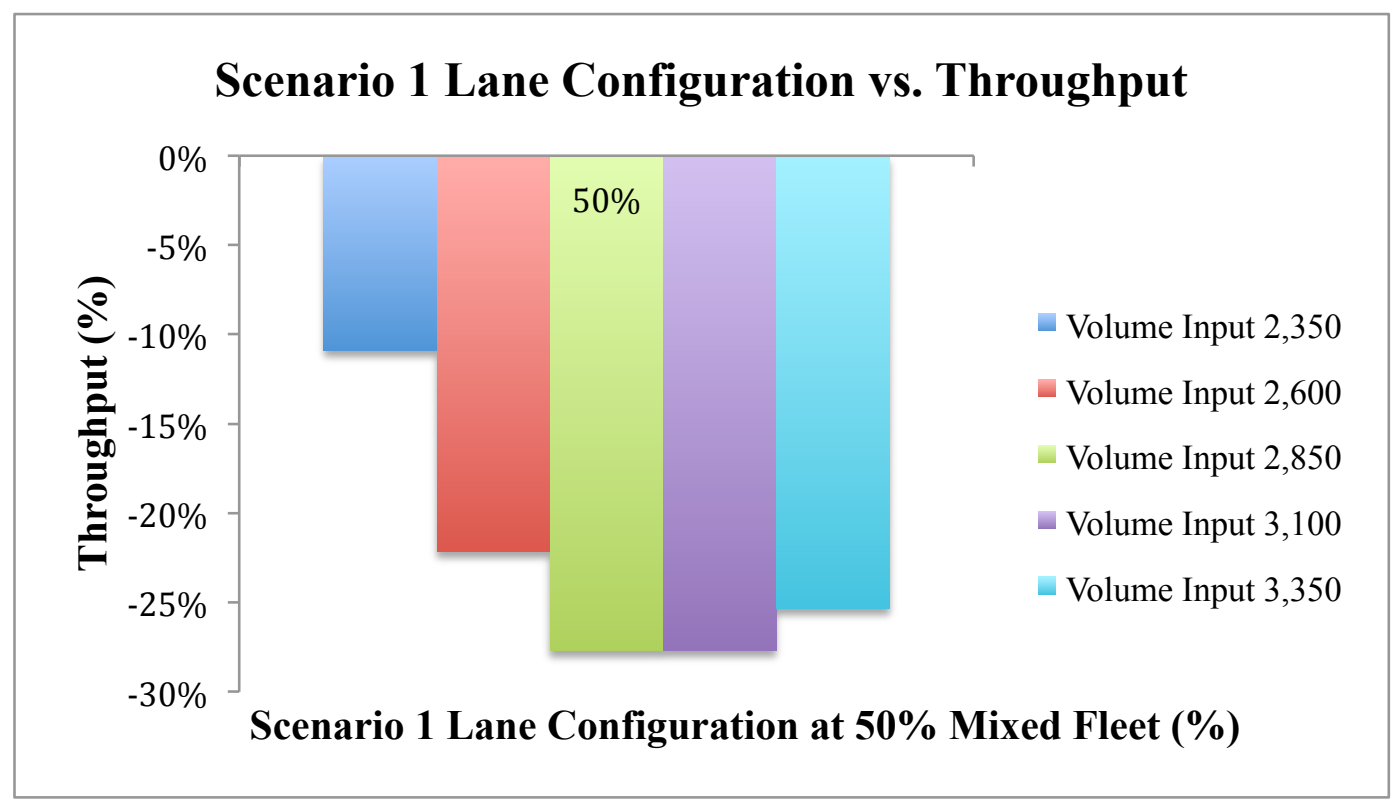

Figure 10: Scenario 1 of the lane configuration for $50 \%$ fleet mix 


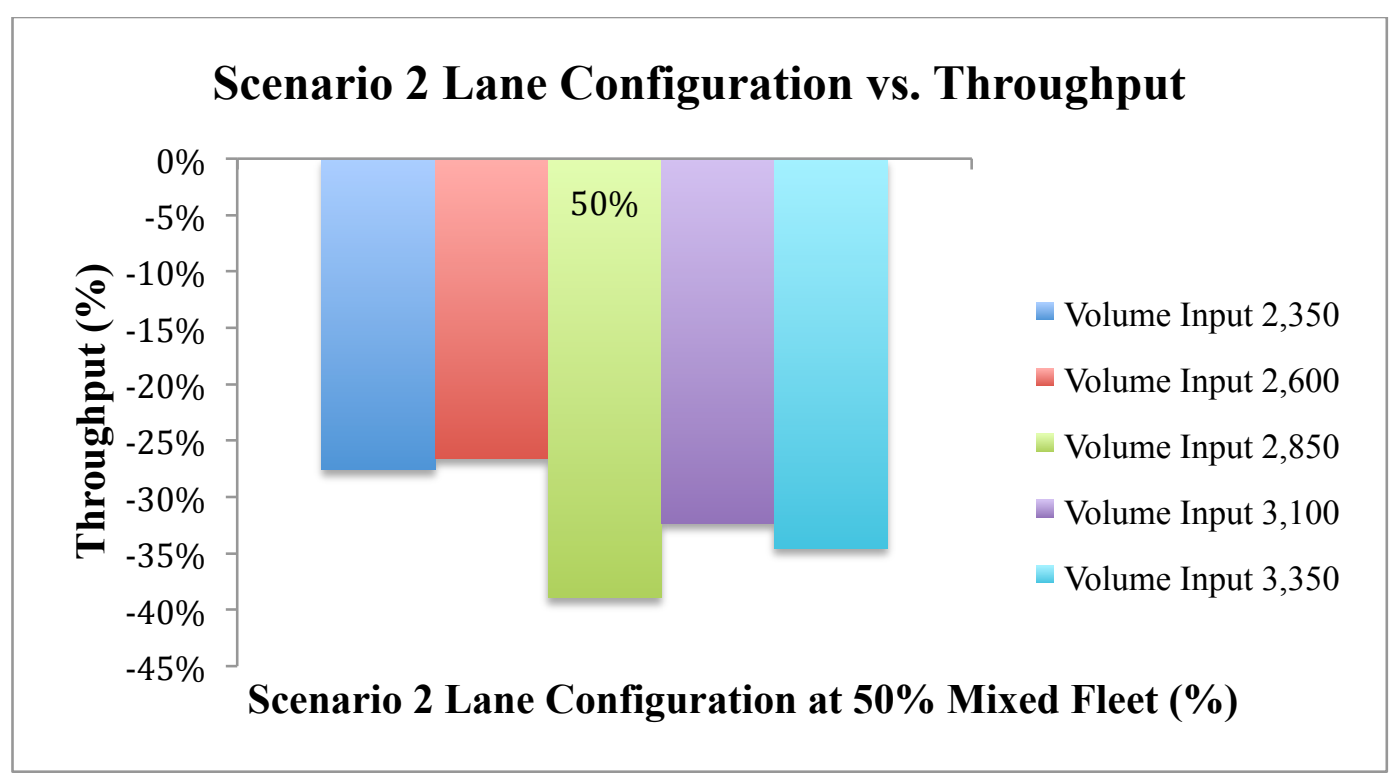

Figure 11: Scenario 2 of the lane configuration for $50 \%$ fleet mix

Both Scenarios of the lane configuration have shown a negative impact on freeway throughput when compared to the $50 \%$ fleet mix scenario of free lane changing. That is also due to the congestion caused by the regular vehicles on its assigned lane. Moreover, travel time and delay have increased again, and the speed has decreased for the lane configuration scenarios. 


\section{Chapter 5 CONCLUSIONS AND RECCOMENDATIONS}

\subsection{Conclusions}

The purpose of the thesis is to model the autonomous vehicles in the microsimulation software VISSIM, and to test their impact on freeway throughput, delay and travel time. The following conclusions can be made from this study:

- Microsimulation tools such as VISSIM can be effectively used to model autonomous vehicles. VISSIM incorporate three different driving models, and for the purpose of this research only Weidemann 1999 car following model was used to complete this study.

- The Weidemann 1999 car following model consists of ten calibration parameters that control the driver's behavioral characteristics. In order to properly model the autonomous vehicles in VISSIM, six of these parameters have been adjusted and the rest were kept at default.

- A 6.5 miles realistic section of I-79 was chosen to test the impact of autonomous vehicles on freeway throughput. Five different models were created with five different demand input volume. Each model consists of seven scenarios of fleet mix to test the impact of autonomous vehicles on freeway throughput. There was an increase on freeway throughput that ranged between 6-18\%.

- A 5 miles conceptual network was also created to test the impact of autonomous vehicles on freeway throughput. Five different models were created with seven different scenarios as well. The autonomous vehicles have 
shown a significant impact of freeway throughput where the freeway throughput has increased between 5-22\% with different scenarios.

- The realistic network of I-79 and the conceptual network were used to test the impact of various freeway lane configuration on efficiency of mixed traffic flow including regular and autonomous vehicles. Both case have shown a negative impact on freeway throughput.

\subsection{Recommendations}

As is the case with any research effort, further research is required as follows:

1- Develop more complex realistic networks to test the impact of autonomous vehicles on freeway throughput.

2- Test the impact of autonomous vehicles of freeway throughput with narrow lanes.

3- Study the impact of autonomous vehicles using different simulation software's.

4- Use shorter headway time to study the impact of autonomous vehicles on freeway throughput.

5- Develop a network that includes more vehicle types such as bikes.

6- Study the impact of autonomous vehicles on urban roads. 


\section{REFERENCES}

Bierstedt, J., Gooze, A., Gray, C., Peterman, J., Raykin, L. and Walters, J. (2014). Effects of next-generation vehicles on travel demand and highway capacity. FP Think Working group publication, 1-31.

Litman, T. (2014). Autonomous Vehicle implementation predictions. Implications for transport planning. Victoria Transport Policy Institute Publication, 1-20.

Pinjari, A., Augustin, B. and Menon, N. (2013). Highway capacity impacts of autonomous vehicles: an assessment. Center for Urban Transportation Research Publication. University of South Florida, pp. 1-17.

Reich, S. (2013). Automated and autonomous vehicles and managed lanes. Center for Urban Transportation Research Publication. University of South Florida, 1-10.

Rodoulis, S. (2014). The Impact of autonomous vehicles on cities. Journeys, 1-9.

Federal Highway Administration, Office of Operations. (2013) Reducing Non-Recurring Congestion. http://ops.fhwa.dot.gov/program_areas/reduce-non-cong.htm

Anderson, J. M., Kalra, N., Stanley, K. D., Sorensen, P., Samaras, C. and Oluwatole, O. A. (2014). Autonomous vehicle technology: a guide for policy makers. RAND Corporation publication, 1-217.

Shladover, Steven, Dongyan Su, and Xiao-Yun Lu. (2012). Impacts of Cooperative Adaptive Cruise Control Freeway Traffic Flow. Proceeding of the $91^{s t}$ Annual Meeting of the transportation Research Board.

Bart van Arem, Cornelie J. G. van Driel, and Ruben Visser. (2006). The impact of Cooperative Adaptive Cruise Control on Traffic-Flow Characteristics. IEEE Transaction on Intelligent Transportation Systems, Vol. 7, No. 4.

Stephen Jones and Brian H. Philips. (2013). Cooperative Adaptive Cruise Control: Critical Human Factors Issues and Research Questions. Proceedings of the Seventh International Driving Symposium on Human Factors in Driver Assessment, Training, and Vehicle Design.

L. C. Davis. (2005). Effect of Adaptive Cruise Control Systems on Mixed Traffic Flow Near an On-Ramp. Physics Department, University of Michigan. 
Patcharinee Tientrakool, Ya-Chi Ho, and Nicholas F. Maxemchuk. (2012). Highway Capacity Benefits from Using Vehicle-to-Vehicle Communication and Sensors for Collision Avoidance. Vehicular Technology Conference (VTC Fall).

Hayashi, H., Inomata, R., Fujishiro, R., Ouchi, Y., Suzuki, K., Nanami, T. (2013). Development of pre-crash safety system with pedestrian collision avoidance assist.

Llorca, D., Milanes, V., Parra, I., Gavilan, M., Daza, I. G., Rastelli, J. P. and M. A. Sotelo, M.A. (2011) Autonomous Pedestrian Collision Avoidance Using a Fuzzy Steering Controller. Transactions on Intelligent Transportation Systems, Institute of Electrical and Electronics Engineers (IEEE).

National Highway Traffic Safety Administration (NHTSA). (2012). Preliminary Statement of Policy Concerning Automated Vehicles

Ni, R. and Leung, J. (2011) Safety and liability of autonomous vehicles technologies. $p p$ 1-49.

Talebpour, A. and Mahmassani, H. S. (2014) Influence of autonomous and connected vehicles on stability of traffic flow. $94^{\text {th }}$ annual meeting of the transportation research board and publication in transportation research record.

Levinson, David (2015). Climbing mount next: the effects of autonomous vehicles on society. Department of civil, environmental and geo-engineering, University of Minnesota, USA. pp.1-16.

PTV Planning Transport Verkehr AG. (2011). VISSIM User Manual - Version 5.3-05. Germany.

PTV Planning Transport Verkehr AG. (2003) VISSIM User Manual - Version 3.7. Germany.

PTV Planning Transport Verkehr AG. (2004) VISSIM User Manual - Version 4.10. Germany.

Gomes, Gabriel, Adolf May, and Roberto Horowitz. (2004). "A micro simulation model of a congested freeway using VISSIM." Transportation Research Board Conference.

Olstam, Johan Janson, and Andreas Tapani. (2004). Comparison of car-following models. No. VTI report $960 A$.

Nicholas E. Lownes and Randy B. Machemehl. (2006). Sensitivity of Simulated Capacity to Modification of VISSIM Driver Behavior Parameters. Transportation Research 
Record: Journal of the Transportation Research Board.

Yu Gao. (2008) Calibration and Comparision of the VISSIM and INTEGRATION Microscopic Traffic Simulation Models. Research.

Behrisch, Michael, et al. (2011) Sumo-simulation of urban mobility-an overview. SIMUL 2011, The Third International Conference on Advances in System Simulation.

Highway Capacity Manual. (2010). Transportation Research Board. Washington, D.C.

Tom V. Mathew. Car Following Models. N.p., n.d. Web. 2014. http://www.civil.iitb.ac.in/tvm/1111_nptel/533_CarFol/plain/plain.html

Nicholas J. Garber, Lester A. Hoel. (2009). Traffic and Highway Engineering $4^{\text {th }}$ edition. ISBN 0495082503. University of Virginia. 


\section{APPENDIX}

